\title{
Can the Paris deal boost SDGs achievement? An assessment of climate mitigation co-benefits or side-effects on poverty and inequality
}

\author{
Lorenza Campagnolo ${ }^{\mathrm{a}, *}$, Marinella Davide ${ }^{\mathrm{a}, \mathrm{b}, \mathrm{c}, 1}$ \\ ${ }^{a}$ Fondazione Eni Enrico Mattei (FEEM) and Euro-Mediterranean Center on Climate Change (CMCC), Italy \\ ${ }^{\mathrm{b}}$ Belfer Center for Science and International Affairs, Harvard University, USA \\ ${ }^{\mathrm{C}} \mathrm{Ca}$ ' Foscari University of Venice, Italy
}

\section{A R T I C L E I N F O}

Article history:

Accepted 18 May 2019

\section{JEL classification:}

C23

C68

Q56

Keywords:

SDGs

Poverty

Inequality

CGE model

Mitigation policy

Paris agreement

\begin{abstract}
A B S T R A C T
The paper investigates potential synergies and trade-offs between emission reduction policies and sustainable development objectives. Specifically, it provides an ex-ante assessment that the impacts of the Nationally Determined Contributions (NDCs), submitted under the Paris Agreement, will have on the Sustainable Development Goals (SDGs) of poverty eradication (SDG1) and reduced income inequality (SDG10). Through this research we aim at answering the following questions: does mitigation policy always imply a trade-off with development objectives? If this is the case, what is the magnitude of the effect of the new international climate architecture on poverty and inequality? By combining an empirical analysis with a modelling exercise, the paper estimates the future trends of poverty prevalence and inequality across countries in a reference scenario and under a climate mitigation policy with alternative revenue recycling schemes. Our study finds that a full implementation of the emission reduction contributions, stated in the NDCs, is projected to slow down the effort to reduce poverty by $2030(+4.2 \%$ of the population below the poverty line compared to the baseline scenario), especially in countries that have proposed relatively more stringent mitigation targets and suffer higher policy costs. Conversely, the impact of climate policy on inequality shows opposite sign but remains very limited. If financial support for mitigation action in developing countries is provided through an international climate fund, the prevalence of poverty will be slightly reduced at the aggregate level, but the country-specific effect depends on the relative size of funds flowing to beneficiary countries and on their economic structure. The output of our analysis contributes to the emerging literature on the linkages between climate change policy and sustainable development, although we capture only partially the complex system of interrelations and feedbacks proper of the SDGs. Moreover, due to its policy relevance, it further enriches the debate on the implementation of the Paris Agreement and its climate finance tools.
\end{abstract}

(C) 2019 Elsevier Ltd. All rights reserved.

\section{Introduction}

At the end of 2015, two summit meetings took place that will lead to a redefinition of the international policy environment in the near future. In September 2015, the United Nations adopted the Sustainable Development Goals (SDGs), updating the Millennium Development Goals by defining broader and more ambitious

\footnotetext{
* Corresponding author at: Euro-Mediterranean Center on Climate Change (CMCC), Edificio Porta dell'Innovazione - Piano 2, Via della Libertà, 12, 30175 Marghera-Venice, VE, Italy.

E-mail addresses: lorenza.campagnolo@cmcc.it (L. Campagnolo), marinella. davide@cmcc.it (M. Davide).

${ }^{1}$ Euro-Mediterranean Center on Climate Change (CMCC), Edificio Porta dell'Innovazione - Piano 2, Via della Libertà, 12, 30175 Marghera-Venice (VE), Italy.
}

development objectives that apply to all countries. Through 17 SDGs, the new 2030 Agenda for Sustainable Development addresses economic, social, and environmental sustainability and designs a pathway toward inclusive green growth. Three months later, in December 2015, the 21st UNFCCC Conference of Parties (COP 21) adopted the "Paris Agreement", which aims to strengthen the global response to climate change through a new regime of country-driven emission reduction and adaptation plans. In particular, the Agreement contemplates three major objectives: i) maintaining the increase in the global average temperature to well below $2{ }^{\circ} \mathrm{C}$ above pre-industrial levels, with efforts to limit the increase to $1.5^{\circ} \mathrm{C}$; ii) increasing the ability to adapt to the adverse impacts of climate change and fostering climate resilience; and iii) mobilizing consistent finance flows to achieve mitigation and adaptation objectives (UNFCCC, 2015). 
Both frameworks represent a breakthrough from previous international attempts aimed at addressing these global challenges. In the 2030 Agenda for Sustainable Development, environmental and climate change objectives are integrated with traditional economic and development objectives, such as eliminating poverty and improving health and education, rather than treating these issues separately. In the Paris Agreement, the new bottom-up structure fosters a wider participation of countries than had been achieved under previous agreements. This includes developing countries, which are allowed to propose their national contribution to the effort to deal with climate change by taking into account their national development priorities. This shift recognizes the need to adopt a comprehensive approach to global challenges, one capable of considering developmental and environmental challenges as intertwined. Clearly, a strong potential for interactions exists between efforts to achieve sustainable development goals and efforts to address climate change.

Early research into this topic helped to conceptualize the possible links between climate change mitigation policy and sustainable development. Some have suggested ways to strengthen potential synergies (Beg et al., 2002), and others have discussed opportunities for integrated policy making (Swart, Robinson, \& Cohen, 2003). More recent work has focused on quantifying the synergies and trade-offs between mitigation policy and other objectives (von Stechow et al., 2015, 2016). Despite these notable efforts, current integrated modelling research remains confined to sectoral studies offering a limited view on possible co-effects and focusing on a narrow set of specific objectives, such as the effect of mitigation on economic growth (Jakob \& Steckel, 2014), access to energy (Steckel, Brecha, Jakob, Strefler, \& Luderer, 2013), air pollution (Rao et al., 2016) or a subset of them (Iyer et al., 2018).

This paper broadens the current perspective by providing an exante assessment of the co-benefits and side-effects emerging from these new policy settings. In particular, this paper analyses how the commitments made by countries under the Paris Agreement will influence those countries' achievement of two specific SDGs: the prevalence of poverty (SDG1) and inequality (SDG10). The eradication of extreme poverty and the reduction of inequality are among the highest priorities in the broader effort to ensure sustainability worldwide, and their achievement is crucially intertwined with progress in other SDGs. Therefore, given the linkages between environmental and sustainable development objectives, analysing the effects of environmental regulation on development is critical.

The topic has a great importance for policy, since concern about possible trade-offs between climate change interventions and economic development are still perceived by developing countries as major obstacles to taking action to limit their greenhouse gas emissions. Indeed, it has been widely recognized that poorer segments of society are generally more vulnerable to negative climate impacts, especially where such events interact with and amplify non-climatic stressors (Olsson et al., 2014). It has also been argued that the costs of emissions reduction policies may further negatively impact the poorest households, absent measures to offset the distributional impacts of those policies (Grottera, Pereira, \& La Rovere, 2017; Jakob and Steckel, 2014; Goulder, 2013; Büchs, Bardsley, \& Duwe, 2011; Callan, Lyons, Scott, Tol, \& Verde, 2009).

Existing cross-country research on the impact of mitigation policies on poverty or inequality in developing countries has been narrowly focused (Barbier, 2014). Prior to the Paris Agreement, the burden of the international mitigation action was primarily placed on developed countries. Early research efforts have consequently been focused on the effect of the Kyoto Protocol's commitments of Annex I (or developed) countries on non-Annex I (developing) nations, with a wide literature exploring the impacts of forest carbon mechanisms or Clean Development Mechanism (CDM) projects on poverty and livelihoods (Olsen, 2007; Olsson et al., 2014). Among the most prominent modelling exercises quantifying poverty impacts of mitigation targets across countries, Hussein, Hertel, and Golub (2013) estimate that a carbon tax on fossil fuels in Annex I countries leads to poverty reduction in most of the nonAnnex I countries. However, when a forest carbon sequestration incentive (paid by Annex I parties) is added in the developing regions, the effect is reversed, with most low-income countries showing an increase in returns to the land, leading to reduced agricultural output and increased food prices.

Against this background, this paper aims at further enriching the debate by exploring the magnitude of impact of the new global climate policy framework - including mitigation contributions by both developed and developing countries - on poverty and inequality.

From a methodological point of view, our approach combines an empirical analysis with a modelling exercise performed by using a recursive-dynamic Computable General Equilibrium (CGE) model developed and enriched with SDGs indicators. CGE models are well-suited to assess the performance of economic indicators. Moreover, past modelling literature has highlighted the fact that they are also a powerful tool for assessing the evolution of key environmental indicators (Bohringer \& Löschel, 2006). Modelling social indicators in a CGE framework, however, is a difficult task, especially when these imply dispersion measures such as poverty prevalence and inequality at the core of SDG1 and SDG10. We overcome the representative agent structure proper of CGE models by relying on empirical literature and directly estimating the relationships between indicators and endogenous variables of the model (Bourguignon, Ferreira, \& Lustig, 2005; Ferreira, Leite, \& Ravallion, 2010; Montalvo \& Ravallion, 2010). We characterise the future trend of poverty prevalence and inequality in a baseline scenario, which is then used as a term of comparison to assess the impact of climate policy under different recycling schemes.

This approach allows us to shed light on the possible ancillary costs and benefits of mitigation policies. We are able to assess whether there is a trade-off between climate policy and economic/social development, and therefore how the implementation of climate policy could help to achieve other SDGs. Our results show that the full implementation of the emission reduction contributions as stated in the NDCs will slow down the effort to reduce poverty by 2030 . The effect is greater in countries that have proposed a relatively more stringent carbon mitigation target, though the magnitude of the effect is limited. The impact on inequality is even smaller and depends on adjustments of sectoral value added. When the revenues from the climate policy are recycled contributing to an international climate fund, aimed at further supporting mitigation action in developing countries, the prevalence of poverty is slightly reduced at the aggregate level compared to the mitigation scenario, but it remains above the baseline levels.

The remainder of the paper is organized as follows. Section 2 briefly discuss the indicators selected to depict poverty and inequality, and describes their past trends. Section 3 reviews existing literature to estimate the determinants of inequality and poverty. Section 4 describes the modelling framework. Section 5 presents future projections of inequality and poverty compared to a baseline scenario. Section 6 briefly describes the policy context, including the NDCs presented under the Paris Agreement. Building on previous assumptions, Section 7 projects the future trends of inequality and poverty by assuming that the mitigation efforts under the Paris Agreement are fully implemented. Finally, Section 8 analyses the impact on SDGs of an international fund to supporting efforts in meeting NDCs by developing countries. Main conclusions are summarized in the final section. 


\section{Inequality and poverty within the Agenda 2030: Measures and past trends}

Of the seventeen Sustainable Development Goals (SDGs), outlined by the UN in Agenda 2030, two directly address poverty and inequality. In particular, SDG1 calls for ending poverty in all its forms everywhere. SDG10 calls for reducing inequality within and between countries (United Nations, 2015).

Both SDG1 and SDG10 are further articulated into more detailed targets that can be monitored through a set of quantitative and qualitative indicators (United Nations, 2017). SDG1 is divided into 5 specific targets, the first of which calls for the eradication of extreme poverty, defined as the number of people living below the international poverty line. The four remaining components of SDG1 address additional important aspects, such as social protection, access to resources and basic services, and vulnerability to economic, social and environmental shocks. We agree that an effective understanding of poverty comprehends its multidimensional nature, however, for the purpose of this study we use the poverty headcount ratio at international poverty line of $\$ 1.90$ per day (2011 PPP) (World Bank, 2018).

Regarding SDG10, which addresses income inequality within and between countries, we concentrate specifically on SDG10.1 aimed at achieving "income growth of the bottom 40 per cent of the population at a rate higher than the national average" (United Nations, 2015). ${ }^{2}$ Selecting the most suitable indicator to track progress on SDG10.1 is a complex matter. The Gini Index, widely adopted for national statistics, could have been the most natural candidate, but we have opted instead for the Palma Ratio, defined as "the ratio of the top $10 \%$ of population's share of gross national income (GNI), divided by the poorest $40 \%$ of the population's share of GNI". Our choice is motivated by three main points: i) the Gini Index is oversensitive to changes in the middle of income distribution and instead is less sensitive to changes at the extremes (Atkinson, 1970). This index seems not an ideal tool for analysing current inequality patterns characterised by stable income share of middle classes and high fluctuations on the tails (Cobham, Schlogl, \& Sumner, 2016). ${ }^{3}$ Palma ratio that focuses on the top and bottom classes of income distribution looks more appropriate. Furthermore, (ii) Palma is easy to compute and more direct to communicate to policymakers (Cobham et al., 2016) and (iii) Palma ratio is directly linkable to SDG 10.1 target.

The figures below report the past trends for the two selected indicators worldwide and by geographic area (Figs. 1 and 2). ${ }^{4}$ 1990-2014 data from the World Development Indicators (WDI) (World Bank, 2018) and World Income Inequality Database (WIID3.4) (UNU-WIDER, 2017) show that the poverty headcount ratio constantly lowered worldwide, from about 34\% in 1992 to $14 \%$ in 2012 . This was mainly driven by steep decreases in the East and South Asian countries, whereas the reduction was milder in sub-Saharan Africa.

Inequality, measured as a population-weighted Palma ratio, increased slightly worldwide until 1996, and has since been decreasing. The drastic decline in inequality in Latin America since

\footnotetext{
2 Acknowledging the importance of other inequality dimensions such as social, economic and political exclusion, opportunities and representativeness, we prefer a quantitative and widely available indicator of income inequality.

${ }^{3}$ It is worth noticing that Gini Index is not included among the proposed indicators to measure progresses in achieving SDGs by the Inter-agency and Expert Group on Sustainable Development Goal Indicators (United Nations, 2017).

${ }^{4}$ World and regional-aggregate past trends of poverty and inequality are meant to give a general overview of the matter and overlook strong country-specific heterogeneity that will be better explored in Section 3 .
}

2000 has driven the global pattern of inequality reduction, aided by more modest declines in sub-Saharan Africa. North America is the only region showing a clear increase in the disparities between rich and poor.

Observing past trends of extreme poverty and inequality is a starting point, but it is fundamental to understand the determinants of these two indicators, in order to draw conclusions on their future patterns.

\section{Inequality and poverty determinants in empirical and modelling literature}

A broad empirical literature elucidates the determinants of poverty reduction from a cross-country perspective. Ravallion and Chen (1997) identify the growth of average per capita income as the main factor in reducing poverty. Ravallion (1997, 2001) and Heltberg (2002) highlight the importance of the structure of income distribution, which may undermine the inclusiveness of per capita income growth. Other country-specific empirical analyses also highlight the importance of sectoral growth patterns in explaining differentiated rates of poverty reduction across regions (Ferreira et al., 2010; Montalvo \& Ravallion, 2010).

Relevant literature on macro-economic modelling is more dispersed and, in general, focuses on single-country analyses. Nevertheless, two strands can be identified: the Microsimulation approach, which elaborates the outcome of the CGE model by using a microsimulation module that downscales the macro-economic result at the individual or group-level (Bussolo \& Lay, 2003; Hertel, Verma, Ivanic, \& Rios, 2011; Hilderink, Lucas, \& Kok, 2009; Lofgren, Cicowiez, \& Diaz-Bonilla, 2013); and the MultiHousehold approach that directly integrates microdata in the macro-economic model and allows an endogenous poverty evolution (Boccanfuso, Decaluwé, \& Savard, 2003).

Choosing the modelling approach depends greatly on data availability. The lack of country-specific data on the varied composition of income sources (and consumption expenditure) by income quantile makes it impracticable to use a Multi-Household approach and even a complex Microsimulation module, as in Bussolo and Lay (2003).

To compensate for a lack of available data, we build upon Lofgren et al. (2013), Hilderink et al. (2009), and other empirical literature on the topic, and run a panel regression in order to understand the link between the measure of poverty prevalence (Poverty headcount ratio below poverty line at $2011 \$ 1.90$ a day), average per capita income (GDPPPP2011 per capita), and the indicator of unequal income distribution (Palma ratio). Furthermore, we included country fixed effect $\left(c_{i}\right)$.

$\ln \left(P O V_{i, t}\right)=\beta_{0}+\beta_{1} \ln \left(G D P P P P p c_{i, t-1}\right)+\beta_{2} \ln \left(\right.$ Palma $\left._{i, t-1}\right)+c_{i}+\varepsilon_{i, t}$

In order to account for the heteroskedasticity and autocorrelation that characterise our panel, we use a linear regression model with robust standard errors, including a first order correlation within each panel. The data source is the WDI (World Bank, 2018) for both poverty prevalence and income deciles, but for the latter we filled missing information using the WIID3.4 (UNUWIDER, 2017). The panel considers 130 countries, both developed and developing, in the period 1990-2014 (Table 1).

The regression results are in line with existing literature and show a negative correlation between poverty prevalence and income per capita. That is, the number of people below the poverty line tends to shrink as GDP per capita increases. However, increases in the Palma ratio, concentration of income in the top 


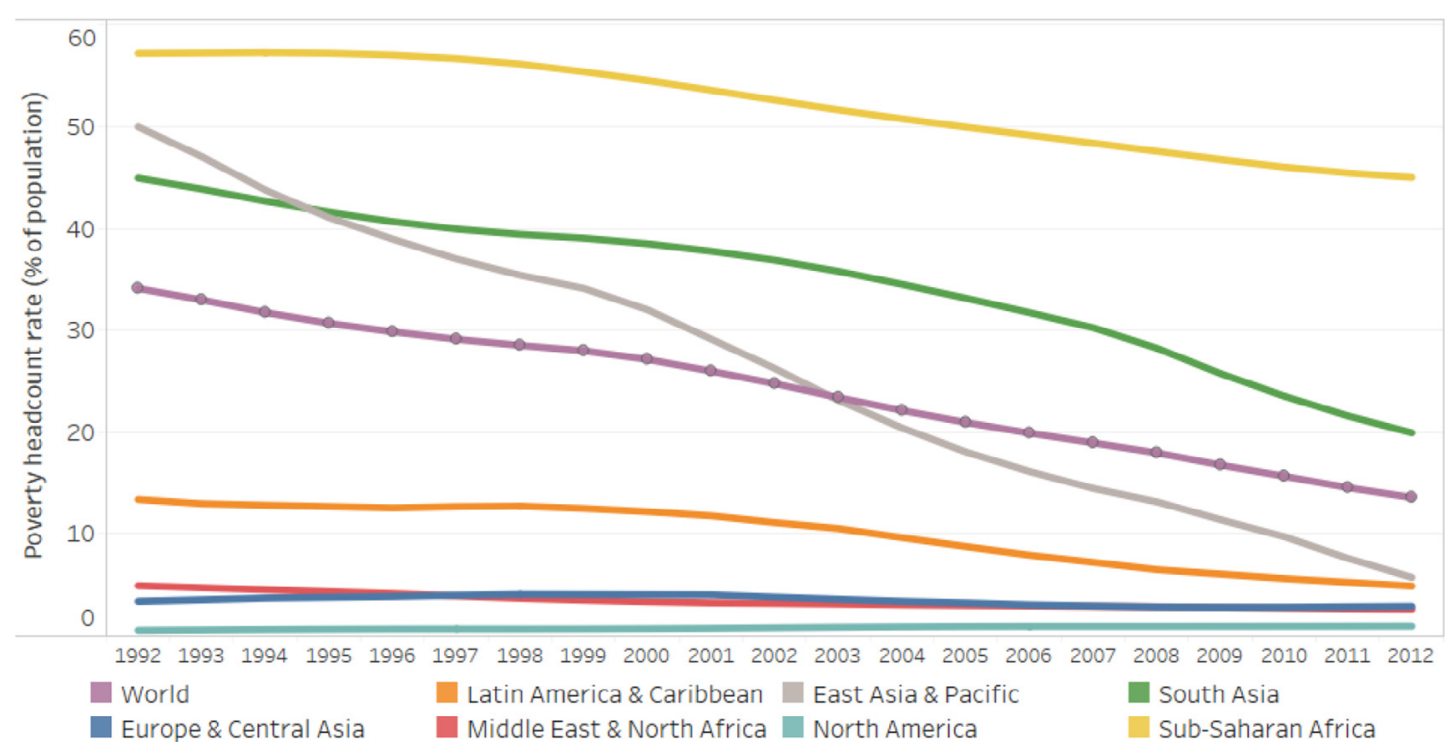

Fig. 1. Poverty headcount ratio at 1.90\$PPP per day for country aggregates and worldwide, 1992-2012 (5-year weighted average).

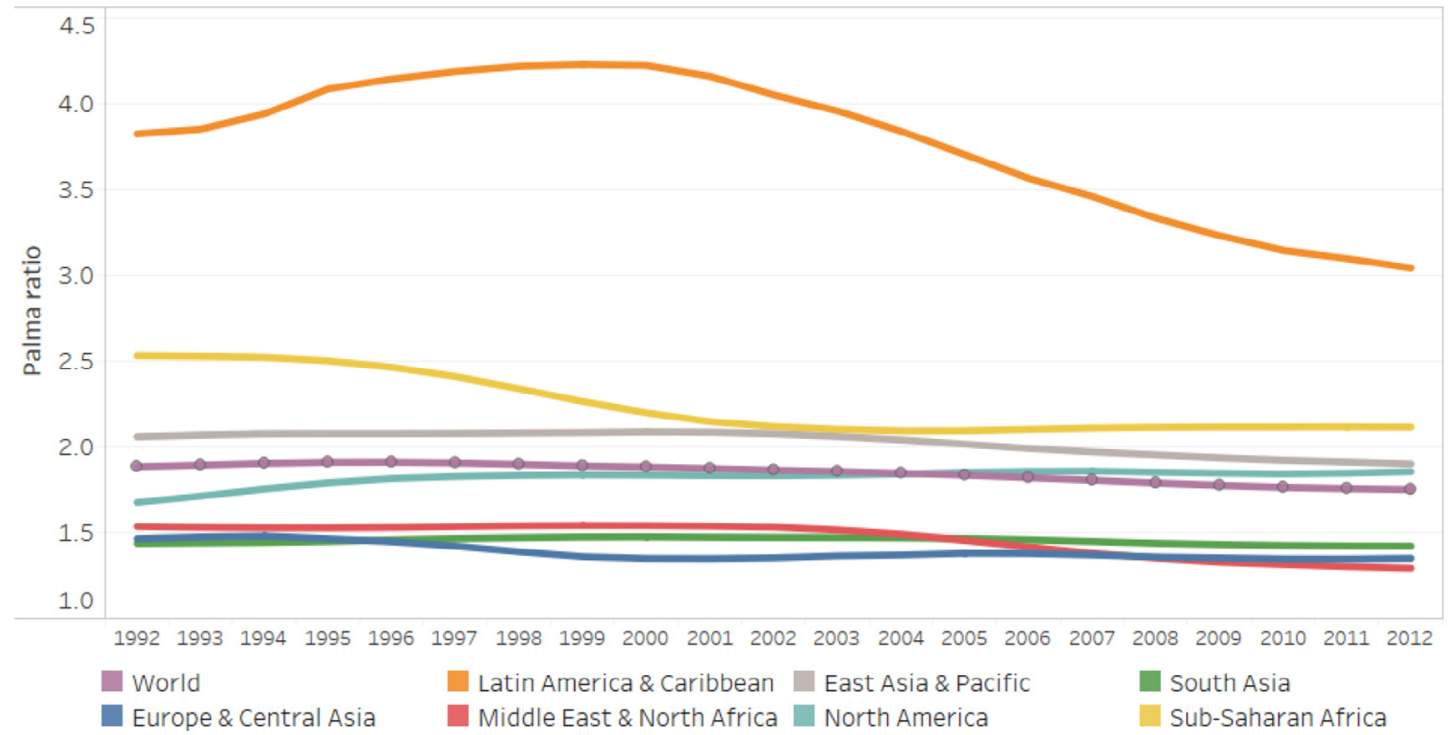

Fig. 2. Palma ratio trend for country aggregates and the World, 1992-2012 (5-year weighted average).

Table 1

Linear regression model for panel corrected standard errors for Poverty headcount ratio at $\$ 1.90$ a day.

\begin{tabular}{ll}
\hline & $\ln \left(\mathrm{POV}_{\mathrm{i}, \mathrm{t}}\right)$ \\
\hline $\ln \left(\mathrm{GDPPPPp}_{i, t-1}\right)$ & $-3.1371^{* * *}$ \\
& $(0.000)$ \\
Palma $_{i, t-1}$ & $0.1286^{* *}$ \\
& $(0.014)$ \\
Constant & $28.0526^{* * *}$ \\
& $(0.000)$ \\
Observations & 975 \\
Number of country & 130 \\
$\mathrm{R}^{2}$ & 0.842 \\
Robust $\mathrm{p}$ value in parentheses & \\
\hline${ }^{* * *} \mathrm{p}<0.01 ;{ }^{* *} \mathrm{p}<0.05 ;{ }^{*} \mathrm{p}<0.1$ &
\end{tabular}

decile with respect to the poorest $40 \%$ of population, is correlated with more people below the poverty line.

The determinants of income inequality are even more complex to disentangle than the causes of extreme poverty. Empirical studies suggest reductions in income inequality within and among countries have been achieved since the 1980s, especially within developing countries (Ravallion, 2003, 2014). The determinants of this pattern can vary. In country-specific analyses, a major role

\footnotetext{
${ }^{5}$ In Appendix I, the fitted poverty prevalence for the analyzed 45 country/macroregions is compared with historical data. We also provide a robustness check on poverty prevalence estimates replacing the Palma ratio with the Gini index as regressor. Variable significance, coefficient signs, magnitude and explanatory power do not change.
} 
can be played by the differential in labour productivity between agricultural and non-agricultural sectors (Bourguignon \& Morrisson, 1998); reforms in the labour market; or an expansion of education and changes in population dynamics (Bourguignon et al., 2005). In cross-country analyses, the principle variables considered include sectoral wage differentials between skilled and unskilled labour; globalization; education rates; market reforms; and policy interventions (Alvaredo \& Gasparini, 2015).

Regarding the macro-economic modelling literature (in particular CGE frameworks), income distribution is generally assumed to remain constant over time or exogenously imposed (van der Mensbrugghe, 2015). An alternative option for tackling the possible evolution of inequality within a country is the MultiHousehold approach, which allows for a heterogeneous response to macro-sectoral dynamics of household income and consumption choices. However, given the global perspective of our analysis and the lack of available data, modelling inequality with a MultiHousehold approach is unfeasible.

Our dependent variable is the Palma ratio, computed as the share of GDP held by the richest $10 \%$ of the population, and that held by the poorest $40 \%$. Our data source on income and consumption distributions is the WDI (World Bank, 2018), but we complemented it using the WIID3.4 (UNU-WIDER, 2017). As explanatory variables, we consider some macroeconomic variables drawn from the World Development Indicator database and World Governance Indicators (World Bank, 2018), which are consistent with the literature, characterised by a good country and year coverage, and directly linkable to endogenous variables in our CGE model.

The cross-country panel regression has the following specification:

$$
\begin{aligned}
\ln \left(\text { Palma }_{i, t}\right)= & \beta_{0}+\beta_{1} \ln (\text { PEduExp_pc } \\
& \times \ln \left(\text { AgriVA_t }_{i, 1}\right)+\beta_{2} \\
& +\beta_{4} \ln \left(\text { CorruptCtrl }_{i, t-1}\right)+\beta_{3} \ln \left(\text { hIndVA_sh }_{i, t-1}\right) \\
& +\beta_{6} d_{-} \text {Unempl }_{i, t, t}+t+c_{i}+y_{t}+\varepsilon_{i, t}
\end{aligned}
$$

where Palma $_{i, t}$ is the value of Palma ratio for country $i$ at time $t$. The explanatory variables are: the Public Education Expenditure per capita (PEduExp_pc); the sectoral composition of the Value Added (VA), i.e. the share of VA from agriculture (AgriVA_sh) and heavy industry (hIndVA_sh); an indicator on the perception of corruption control (CorruptCtrl) ${ }^{6}$; the unemployment rate (Unempl); a dummy that distinguishes whether the dependent variable derives from a consumption or income distribution $\left(d_{-} c_{-} i\right)^{7}$ and a time trend $(t)$. In addition, we include country $\left(c_{i}\right)$ and year $\left(\boldsymbol{y}_{\boldsymbol{t}}\right)$ fixed effects, the former to account for the effect of time-invariant country characteristics, the latter after rejecting the null hypothesis of all year dummies jointly equal to zero. Furthermore, we use a linear regression model with robust standard errors that account for cross-sectional heteroskedasticity and within-panel correlation.

According to regression results (Table 2), countries with low public education expenditure per capita, low VA share generated in agriculture and industry, low level of corruption control and

\footnotetext{
${ }^{6}$ The indicator of corruption control is part of the WGI's corruption perception index (World Bank, 2018), which measures the perception of abuse in public power for private interests by public workers. These indicators are commonly used in empirical studies instead of other experienced-based indicators, because of the high correlation between them (Treisman, 2007). The indicator of corruption control ranges from approximately -2.5 (weak control) to 2.5 (strong control). In order to include more countries in our estimates, we use interpolated values for Venezuela, Republic of Korea, India, Canada, Germany, Ethiopia and Kenya (linear interpolation between data and constant before/after first/last data).

7 The dummy variable $\left(d_{-} c_{-} i\right)$ assumes value 1 when the dependent variable derives from a consumption distribution, value 0 in the case of income distribution. Following

\begin{tabular}{|c|c|}
\hline & $\operatorname{Ln}\left(P \operatorname{lma}_{i, t}\right)$ \\
\hline $\ln \left(P E d u E x p_{-} p c_{i, t-1}\right)$ & $\begin{array}{l}-0.1428^{* * *} \\
(0.004)\end{array}$ \\
\hline $\ln \left(\right.$ AgriVA_sh $\left.h_{i, t-1}\right)$ & $\begin{array}{l}-0.1844^{* * *} \\
(0.001)\end{array}$ \\
\hline $\ln \left(h I n d V A \_s h_{i, t-1}\right)$ & $\begin{array}{l}-0.0932^{* *} \\
(0.024)\end{array}$ \\
\hline Corrupt_cntr $_{i, t}$ & $\begin{array}{l}-0.0914^{* *} \\
(0.032)\end{array}$ \\
\hline Unempl $_{i, t-1}$ & $\begin{array}{l}0.0062 \\
(0.087)\end{array}$ \\
\hline$d_{-} c_{-} i_{i, t}$ & $\begin{array}{l}0.0213 \\
(0.408)\end{array}$ \\
\hline$t$ & $\begin{array}{l}0.0116^{* * *} \\
(0.000)\end{array}$ \\
\hline Constant & $\begin{array}{l}-21.5724^{* * *} \\
(0.000)\end{array}$ \\
\hline Observations & 700 \\
\hline R-squared & 0.308 \\
\hline Number of country & 122 \\
\hline
\end{tabular}
Alvaredo and Gasparini (2015), we include this dummy in order to account for the wedge between income and consumption-based inequality measures.
}

Table 2

high unemployment are characterised by a high Palma ratio (high inequality). ${ }^{8}$ Implicitly, there is a positive correlation between the inequality and the VA share from manufacturing and services (residual to agriculture and heavy industry shares). This result contributes to the literature on the nexus between sectoral growth and poverty reduction: whether there is consensus about agricultural sector propoor effect, heavy industry and services do not seem effective in shrinking poverty in cross-country analyses (Loayza \& Raddatz, 2010), but in country-specific studies opposite results emerge (Ferreira \& Ravallion, 2009; Ferreira et al., 2010).

It is necessary to understand the main determinants of poverty and inequality in the past to envision the future trend of these two indicators, which will then be characterised by the same relationships with explanatory variables in Eqs. (1) and (2), but mutated socio-economic conditions.

\section{The modelling framework}

Projecting the evolution of inequality and poverty prevalence and assessing the impact of environmental policies on these social indicators require some assumptions on the future socio-economic scenario and a modelling framework to recreate it.

The Inter-temporal Computable Equilibrium System (ICES) model (Eboli, Parrado, \& Roson, 2010) is at the core of our modelling framework (see Appendix II for more details). ICES is a recursive dynamic CGE model: a multi-market model linked to current real economy data observed in the benchmark year, based upon the merging of national social accounting matrices into a global economic database GTAP8 (Narayanan et al., 2012). ICES makes it possible to draw scenario-dependent evolutions of global socioeconomic conditions; in addition, satellite databases on $\mathrm{CO}_{2}$ and non- $\mathrm{CO}_{2}$ emissions and energy volumes connected to production and consumption flows offer insights into the consequences of economic growth on the environment.

\footnotetext{
${ }^{8}$ In Appendix I, we compare the fitted Palma ratio for the analyzed 45 country/ macro-regions with historical data, we run some robustness check on estimation method and on chosen predictor, and we also report the regression results for the two components of Palma ratio (share of GDP held by the richest $10 \%$ of the population, and that held by the poorest $40 \%$ ) GDP in order to disentangle the effects at different points of income distribution.
} 
CGE models mimic the functioning of world economy: optimising agents' behaviours respond to scenario-specific exogenous changes in stocks (population, labour, land) and productivity in order to restore the equilibrium price and the identity between demand and supply in the markets. However, the value added of using a CGE model emerges when it is used for policy assessment because it allows considering second and higher order effects of a policy on the targeted economy and on the rest of the world. The policy generates a price signal in one or more markets that spreads into the others, alters consumption and factor remuneration, and propagates towards other economies through trade.

The two targets illustrated in SDG1.1 and SDG10.1 and the related indicators described in Section 3 go beyond the socioeconomic representation of the world that is proper to CGE models because they are both related to the concept of income distribution across agents within a country, which is not captured in a context of country-representative households of CGE models.

Therefore, we directly exploit the relations identified in Eq. (2) that connect inequality levels to the sectoral structure of the economy, public investment in education, the unemployment rate and corruption control during the period 1990-2014. Assuming the stability of this relation across time, we run an out-of-sample prediction of the Palma ratio for the period 2007-2030, where the historical values of dependent variables are replaced by outputs of the ICES model under the selected scenarios. A similar procedure is used for determining the future poverty rate: the coefficients estimated in Eq. (1), pertaining to the period 1990-2014, are used in an out-of-sample prediction for the period 2007-2030, where the explanatory variables are an endogenous output of the model (GDP per capita) or its derivation (the Palma ratio computed from the out-of-sample predictions of Eq. (2)).

Linking poverty and inequality measures to ICES makes it possible to assess in a single framework the influence of socioeconomic variables and/or policy interventions in achieving SDG1.1 and SDG10.1. Clearly, the analysis depends heavily on the assumptions on the future socio-economic conditions that characterised the baseline scenario.

\section{Inequality and poverty trends up to 2030: The baseline scenario}

As a reference source for our scenario, we use the Shared Socioeconomic Pathways (SSPs) developed by the climate model community (O'Neill et al., 2017). SSPs envision possible future scenarios characterised by differentiated patterns of population, employment and economic growth, energy intensity, emissions, and land cover. These future paths are therefore related to different mitigation/adaptation challenges. Exogenous drivers in the ICES model, such as primary factor productivity, sector-specific efficiency, total factor productivity, population, employed, and energy prices are then used in order to calibrate the endogenous variables - namely GDP, energy use, emissions and value added shares - that characterise a specific SSP.

Our baseline reproduces the Shared Socio-Economic Pathway 2 (SSP2) with $3.6 \mathrm{~W} / \mathrm{m}^{2}$ radiative forcing in 2030 (on the path of $7.5 \mathrm{~W} / \mathrm{m}^{2}$ in 2100 , with a corresponding temperature rise in the range $3.7-4.2^{\circ} \mathrm{C}$ ), and it will then be used as a benchmark to assess the effects of mitigation scenarios arising from the outcome of COP21. SSP2 ${ }^{9}$ is defined as the "middle of the road" scenario, characterised by similar dynamics observed in recent decades, but that imagines some progress in achieving development goals. Income per capita grows globally at a medium pace and also population follows the UN medium projection scenario. Income convergence

\footnotetext{
${ }^{9}$ A more detailed description of SSPs and SSP2 can be found in Appendix II.
}

between countries is slow, but intra-country inequality diminishes. Resource and energy intensity slow down, as well as dependence on fossil fuels. We selected this scenario because is the most conservative (although not necessarily more probable) scenario in terms of socio-economic variable evolution and does not lead to abrupt changes or tipping points that could determine a drastic behavioural shift in the future.

Combining ICES results from the SSP2 scenario with the coefficients estimated in Eq. (2), we are able to estimate how intracountry inequality will evolve up to 2030. Results are reported in Fig. 3, which shows the estimates of the Palma ratio in 2030, compared with the historical figures in 2007 and $2000 .^{10}$

Between 2000 and 2007, the worldwide average Palma ratio decreased by $4.1 \%$, with significant differences amongst countries. Changes in the Palma ratio in this period range from a decrease of $42.3 \%$ in Bolivia to an increase of $36.2 \%$ in South Africa. In the SSP2 scenario, the Palma ratio has a U-shape dropping up to 2012 and then stably rising, with the worldwide average $4.6 \%$ higher in 2030 compared to 2007. The mechanism behind this result is a decrease of income share held by the poorest $40 \%$ of the population $(-4.8 \%)$ whereas the income share of the richest $10 \%$ of the population reduces less $(-0.8 \%){ }^{11}$ The outcome is quite diversified: inequality increases in both, but not all, developed and developing countries. Looking at the macro-regional level, Asia will experience a generalized strong rise of inequality; more heterogeneous is the result in Africa (Ghana and Mozambique are more equal in 2030 than in 2007) and in Latin America (Bolivia is also better off). Considering OECD countries, inequality moderately increases except in Greece, Italy and Spain that experience the highest rise of Palma ratio, and in Sweden where it drops. The major drivers of rising equity are higher agricultural and heavy industry VA share (in developed countries also lower unemployment matters); in developing countries the higher education expenditure per capita plays an important role.

Combining these projections for the Palma ratio with the per capita evolution of GDP, we are able to compute the future path of the poverty rate (Eq. (1)). Fig. 4 illustrates the strong reduction of poverty prevalence in Asia and Sub-Saharan Africa estimated by the model, driven by rising per capita income despite the increase of within-country inequality. The past worldwide trend showed a $30 \%$ reduction of poverty prevalence between 2000 and 2007 . By 2030, the estimated number of people below the $\$ 1.90$ poverty line will have decreased by $93 \%$ compared to the 2007 levels (in absolute terms, this represents 1 billion fewer people living below this poverty line as compared to 2007). Overall extreme poverty persists into 2030 , however, affecting around $1.1 \%$ of the global population (80 million people). Despite this impressive reduction, some countries in Africa and Asia still show significant poverty rates in 2030. In particular, this is the case of the Rest of the Africa region (RoAfrica), Kenya and Uganda, where respectively $5.2 \%, 5.1 \%$ and $3.1 \%$ of the population will live below the $\$ 1.90$ poverty line in 2030 (around 31 million people).

\section{Policy scenario: The Paris Agreement and the NDCs}

The central element of the Paris Agreement are the "Nationally Determined Contributions" (NDCs), which are plans each country

\footnotetext{
10 The out-of-sample predictions use all explanatory variables of (2); moreover, it is worth pointing out that the unemployment rate is an exogenous variable in ICES, and the perception of corruption control is maintained constant after 2013.

11 In Appendix I (Table AI 2), we run two independent regressions, one for the income share held by the poorest $40 \%$ of the population and one for the income share of the richest $10 \%$ of the population. These are the two components of Palma ratio allow better understanding the forces that determine a rise or a drop of the synthetic measure. In Fig. AI I, we compare Palma ratio growth in 2030 using both method and the growth of Palma ratio components.
} 


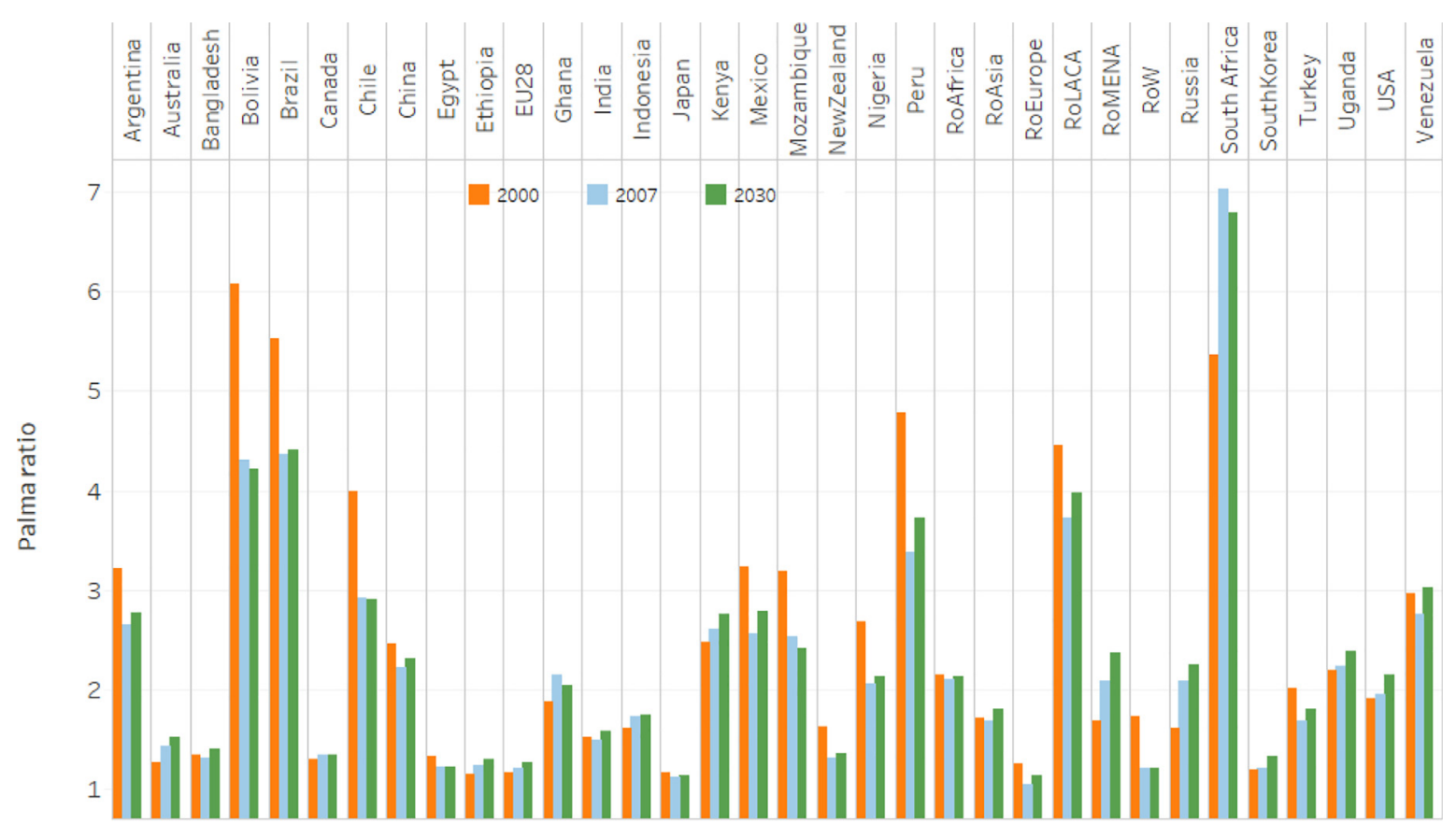

Source: Palma ratio in 2000 and 2007 is computed from WDI; model results are used for 2030.

Fig. 3. Palma ratio in 2000, 2007 and in 2030 SSP2 baseline scenario. Source: Palma ratio in 2000 and 2007 is computed from WDI; model results are used for 2030.

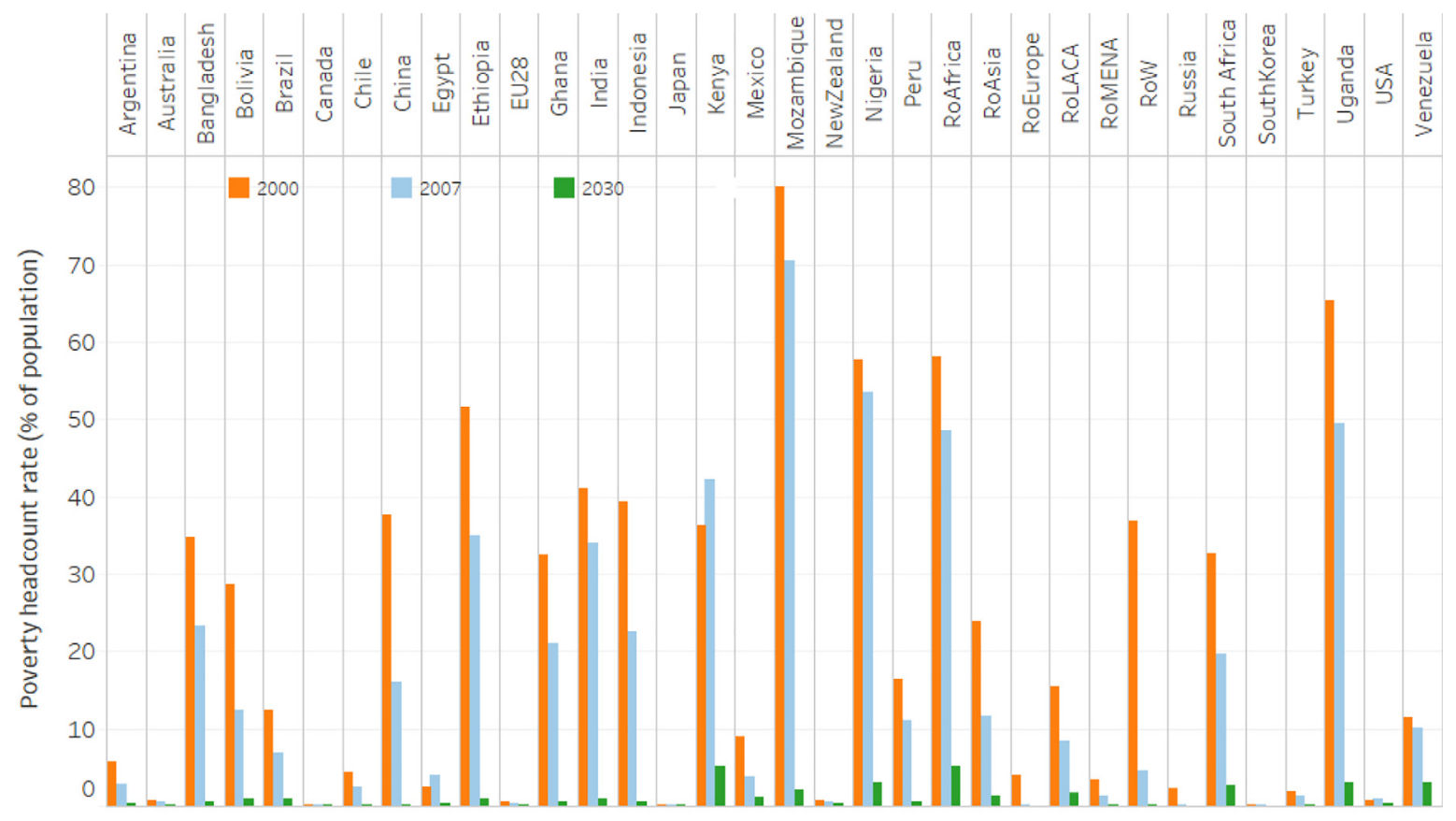

Source: Poverty headcount in 2000 and 2007 is computed from WDI; model results are used for 2030.

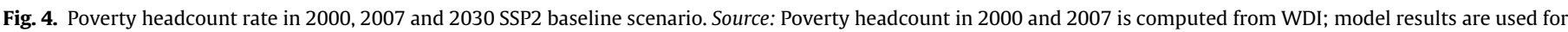
2030.

autonomously determines to deal with climate change from 2020 on. All parties to the Paris Agreement, including both developed and developing countries, are called to adopt and communicate an NDC. Although the NDCs represent a breakthrough in the scope of participation in the international effort to address climate change, they are widely heterogeneous, in both stringency and coverage of mitigation efforts. While developed countries generally frame their contributions in the form of a quantified economywide mitigation effort in comparison to a reference year, developing countries usually refer to emission intensity, or link their emission reduction target to a Business As Usual (BAU) scenario. In addition, most developing countries define both an unconditional and a conditional target: the former to be achieved with internal funds and capabilities, and the latter including a more ambitious 
mitigation effort to be undertaken on the condition that external financial and technical support be provided.

To perform this modelling exercise, we focus on the conditional mitigation objectives stated in the NDCs. ${ }^{12}$ Due to modelling limitations, the GHG emission targets that are part of the NDCs are applied only to $\mathrm{CO}_{2}$ emissions. The emission levels in 2030 are computed by using data from CAIT (WRI, 2016) for countries committing to an emission reduction with respect to a specific year, whereas the SSP2 baseline scenario is used as a reference when the reduction is relative to the BAU scenario. In addition, we also want to assess the effect of these emission reduction measures in the presence of a fund that supports developing countries in realizing their climate change actions. The Paris Agreement reaffirms the commitment of the developed nations to make available increased financial flows to developing countries, starting from the 2020 pledge to mobilize USD 100 billion per year. We simulate this flow of climate finance with the objective of understanding the role that funds like the Green Climate Fund can play in supporting the developing economies in reaching their emission reduction targets. It is worth noting that the Green Climate Fund is one of the many instruments through which international climate finance is going to be mobilised and that the actual funds will come from a variety of public and private sources. While this opens up to relevant research questions about climate finance, here we are mainly interested in the role of additional international flows on clean energy sectors in reducing mitigation costs and consequently benefitting poverty and inequality in developing countries.

Table 3 shows the mitigation objectives considered for each country. In some cases, countries are clustered in regional groups to which a common target is attributed. ${ }^{13}$

The proposed mitigation scenario considers an effort to curb emissions starting in 2013 and assumes that each country achieves its NDC by 2030.

The European Union (EU28) implements an Emission Trading System (ETS), as already foreseen by the EU ETS domestic legislation, while all other countries achieve their contributions unilaterally with a domestic carbon tax. China, India and Chile have expressed their NDCs in terms of emission intensity; this peculiarity is preserved in the modelling policy scenario.

The mitigation scenario is characterised by two different recycling schemes of the revenues collected from the carbon market or the carbon taxes:

- MPOLICY scenario: revenues are redistributed internally;

- MPOLICY + GCF scenario: part of the revenues from the developed countries flows into an international fund aimed at supporting mitigation action in the developing countries. We use the allocation rules of the Green Climate Fund (GCF) as a benchmark (see Section 8). Money is transferred to the developing countries $^{14}$ in Asia, Latin America, the Middle East and Africa, and is used to subsidise specific mitigation-related sectors: namely, Clean Electricity and Research\&Development (R\&D). ${ }^{15}$

\footnotetext{
12 As reported in the UNFCCC's NDC interim registry. For Parties whose NDCs are not yet available we referred to the INDCs available on the UNFCCC's INDC platform.

13 In defining the emission reduction target per aggregates of countries, we computed each country's target emission level in 2030 by converting the otherwise specified NDCs (targets on emission reduction with respect to a specific year, emission levels, emission intensity, and deviation from BAU scenario). The macroregion target emission level is compared to emission levels in the BAU scenario, and the aggregate emission reduction is so derived.

14 Among GCF recipient countries, we included those countries that have up to now selected the National Designated Authorities (excluding China) according to GCF rule: http://www.greenclimate.fund/partners/countries/nda-directory.

15 The allocation of subsidies across the two sectors depends on the magnitude of the sectors itself: e.g. the highest is R\&D VA compared to the Clean Electricity one, the more it is subsidized.
}

\section{Poverty and inequality in the mitigation scenario}

The worldwide implementation of the conditional NDCs yields a $19 \%$ reduction of $\mathrm{CO}_{2}$ emissions at the global level in 2030 with respect to the SSP2 baseline scenario (13\% reduction of GHG emissions). Achieving the mitigation targets (the MPOLICY scenario) imply an economic cost of between $-6.7 \%$ and $+5.6 \%$, computed with respect to the countries' GDP in the baseline scenario in 2030 (Fig. 5).

The situation at the country level is highly heterogeneous. Some countries experience GDP gains as a consequence of absent or loose NDC mitigation targets (Fig. 6). This happens in Japan, China, India, Venezuela, non-EU European countries, Turkey, Egypt, and part of the Middle-East and South Africa, that have relatively lower carbon taxes and, therefore, higher competitive advantages in comparison with other countries.

In particular, China, India and Bolivia are projected to reach higher emission levels under the mitigation policy scenario than in the baseline, experiencing a leakage effect as a consequence of the weak mitigation target stated in their NDCs. On the contrary, countries such as Indonesia, Brazil, Chile, Russia and RoAfrica, whose targets appear to be relatively more stringent, are projected to experience a substantial GDP loss to achieve their mitigation objectives.

To better describe the effects of mitigation policies on SDG1 and SDG10, i.e. poverty prevalence and inequality, we focus only on a narrower set of countries that show high to moderate poverty headcount rates in the base year (2007).

Fig. 7 portrays how inequality (Palma ratio) and poverty headcount ratio and in 2030 are affected by climate policy.

Mitigation policy has a minor impact on countries' inequality (between -3.5 and $+1.5 \%$ ). In general, countries with a stringent mitigation policy experience a reduction of inequality compared to the baseline scenario levels. This is the case in Ethiopia $(-3.5 \%)$, Brazil $(-1.1 \%)$, and Indonesia $(-0.8 \%)$. The forces behind these changes are a country-specific adjustment of sectoral $\mathrm{VA}^{16}$ : the increase in the agriculture share plays a major role in Indonesia whereas in Brazil a slight rise of heavy industry share also intervenes. As explained in Section 3, the empirical analysis on crosscountry historical data highlights that these drivers have a positive impact in reducing inequality. In Ethiopia, the mitigation policy determines a small contraction of agricultural production (negatively effecting the Palma ratio), but fosters heavy industry, which lead to an overall positive effect on the Palma ratio. In fact, despite the contraction of fossil fuel intensive sectors, VA in heavy industry rises because of a switch to clean electricity.

The countries gaining from the climate policy because of a nonstringent NDC show higher inequality than in the baseline scenario. Bolivia and Egypt are clear examples of this pattern, with an increase of approximately 1.5 and $1.3 \%$ in the Palma ratio. The contraction of the (energy intensive) industrial sector, highly dependent on more costly imported energy, is behind this result for Bolivia, whether in Egypt agricultural VA share shrinks.

The outcome in terms of poverty prevalence reduction with respect to the 2030 baseline scenario is mixed and depends on how the composition of both income and inequality is affected by the policy. Worldwide poverty prevalence increases by $4.3 \%$ (nearly 3.4 million people) compared to the baseline scenario. The mitigation policy accelerates poverty reduction especially in RoMENA (-14\%), Egypt (-13\%), Venezuela $(-10 \%)$, India $(-8 \%)$, South Africa $(-5 \%)$ and Mozambique $(-4 \%)$. In these countries, the rise in inequality is more than compensated by economic gains

\footnotetext{
${ }^{16}$ In all policy scenarios, government expenditure in real terms is assumed to be unchanged compared to the baseline scenario one.
} 
Table 3

Emission reduction target in 2030 .

\begin{tabular}{|c|c|c|c|c|c|}
\hline Country & $\begin{array}{l}\text { Target } \\
(\%)\end{array}$ & Target type & Country & $\begin{array}{l}\text { Target } \\
(\%)\end{array}$ & Target type \\
\hline Australia & -27 & Emission reduction wrt 2005 & Venezuela & -20 & Emission reduction wrt $2030 \mathrm{BAU}$ scenario \\
\hline New Zealand & -30 & Emission reduction wrt 2005 & $\begin{array}{l}\text { Rest of Latin America } \\
\text { (RoLACA) }\end{array}$ & -20 & Average mission reduction wrt $2030 \mathrm{BAU}$ scenario \\
\hline Japan & -26 & Emission reduction wrt 2013 & EU28 & -40 & Emission reduction wrt 1990 \\
\hline South Korea & -37 & $\begin{array}{l}\text { Emission reduction wrt } 2030 \text { BAU } \\
\text { scenario }\end{array}$ & $\begin{array}{l}\text { Rest of Europe } \\
\text { (RoEurope) }\end{array}$ & -17 & Average mission reduction wrt $2030 \mathrm{BAU}$ scenario \\
\hline Bangladesh & -15 & $\begin{array}{l}\text { Emission reduction wrt } 2030 \text { BAU } \\
\text { scenario }\end{array}$ & Russia & -27.5 & Emission reduction wrt 1990 \\
\hline China & -62.5 & Emission intensity reduction wrt 2005 & Turkey & -21 & Emission reduction wrt 2030 BAU scenario \\
\hline India & -34 & Emission intensity reduction wrt 2005 & Rest of MENA (RoMENA) & -9 & Average mission reduction wrt $2030 \mathrm{BAU}$ scenario \\
\hline Indonesia & -41 & $\begin{array}{l}\text { Emission reduction wrt } 2030 \mathrm{BAU} \\
\text { scenario }\end{array}$ & Ethiopia & -64 & Emission reduction wrt 2030 BAU scenario \\
\hline $\begin{array}{l}\text { Rest of Asia } \\
\text { (RoAsia) }\end{array}$ & -25 & $\begin{array}{l}\text { Average mission reduction wrt } 2030 \\
\text { BAU scenario }\end{array}$ & Ghana & -45 & Emission reduction wrt 2030 BAU scenario \\
\hline Canada & -30 & Emission reduction wrt 2005 & Kenya & -30 & Emission reduction wrt $2030 \mathrm{BAU}$ scenario \\
\hline USA & -27 & Emission reduction wrt 2005 & Mozambique & -8 & $\begin{array}{l}\text { Emission reduction computed from target emission } \\
\text { levels in } 2030\end{array}$ \\
\hline Mexico & -36 & $\begin{array}{l}\text { Emission reduction wrt } 2030 \text { BAU } \\
\text { scenario }\end{array}$ & Nigeria & -45 & Emission reduction wrt 2030 BAU scenario \\
\hline Argentina & -30 & $\begin{array}{l}\text { Emission reduction wrt } 2030 \text { BAU } \\
\text { scenario }\end{array}$ & Uganda & -22 & Emission reduction wrt 2030 BAU scenario \\
\hline Brazil & -37 & Emission reduction wrt 2005 & South Africa & -22 & $\begin{array}{l}\text { Emission level target in } 2030 \text { is in the range } 398 \text { and } \\
614 \mathrm{Mt} \mathrm{CO} \text {-eq }\end{array}$ \\
\hline Chile & -40 & Emission intensity reduction wrt 2007 & Rest of Africa (RoAfrica) & -33 & Average mission reduction wrt 2030 BAU scenario \\
\hline Peru & -30 & $\begin{array}{l}\text { Emission reduction wrt } 2030 \mathrm{BAU} \\
\text { scenario }\end{array}$ & Rest of the World (RoW) & -36 & Average mission reduction wrt 2030 BAU scenario \\
\hline
\end{tabular}

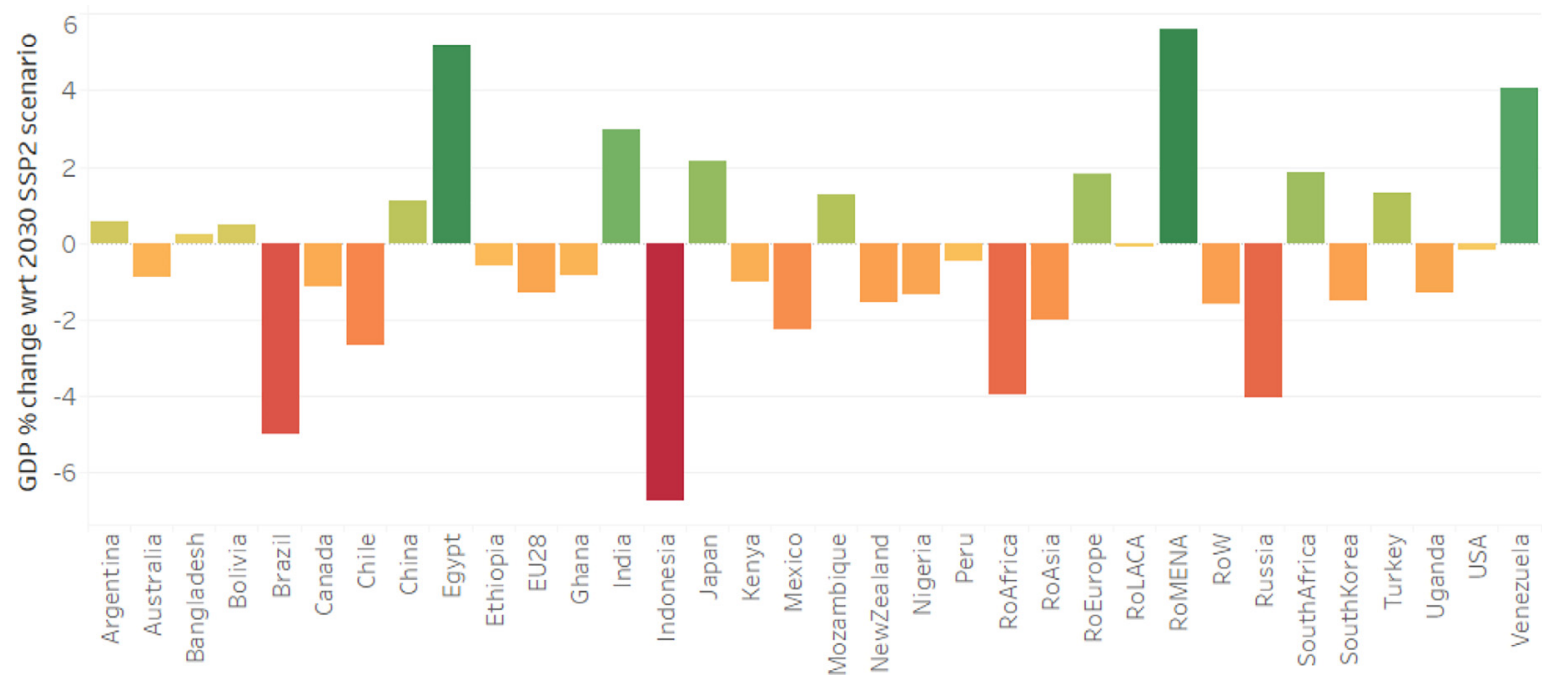

Fig. 5. Mitigation policy cost in terms of GDP in 2030, MPOLICY scenario with respect to SSP2 baseline scenario.

coming from a less stringent climate policy (Fig. 7).

Three countries show the highest rise in poverty prevalence: Indonesia (23\%), Brazil (15\%) and RoAfrica (12\%), where the economic costs of mitigation policy are not compensated by the inequality reduction. Ethiopia is the only country in which the reduction of inequality $(-3.5 \%)$ due to the policy nearly balances the loss induced by mitigation $(-0.6 \%)$ to determine only a limited rise in poverty prevalence compared to the baseline scenario (0.9\%).

\section{Poverty and inequality under the mitigation scenario with a climate fund}

In order to recreate a more realistic scenario of the COP21's aftermath, we design a further recycling rule of carbon revenues, according to which the developed countries, committed to an emission reduction objective in their NDCs, devote a part of their revenues to an international fund aimed at supporting the developing countries' climate action (MPOLICY + GCF scenario). Following the actual allocation rules adopted by the Green Climate Fund's Board so far, we design the fund in order to achieve an "equal balance between adaptation and mitigation" actions, as well as a "geographic balance and a reasonable and fair allocation across a broad range of countries" (GCF, 2014). Since, for the moment, we consider only the support to mitigation actions, our fund will reach $\$ 50$ billion (US\$2007) in 2020 (50\% of the pledged $\$ 100$ billion a year by 2020) and then remains constant. The funds are then distributed across beneficiary countries proportionally to their population share (Fig. 8). Assuming an equal percentage contribution among the donors, to reach the planned amount, they donate 7\% of their carbon revenues up to 2020 and then slightly reduce them 


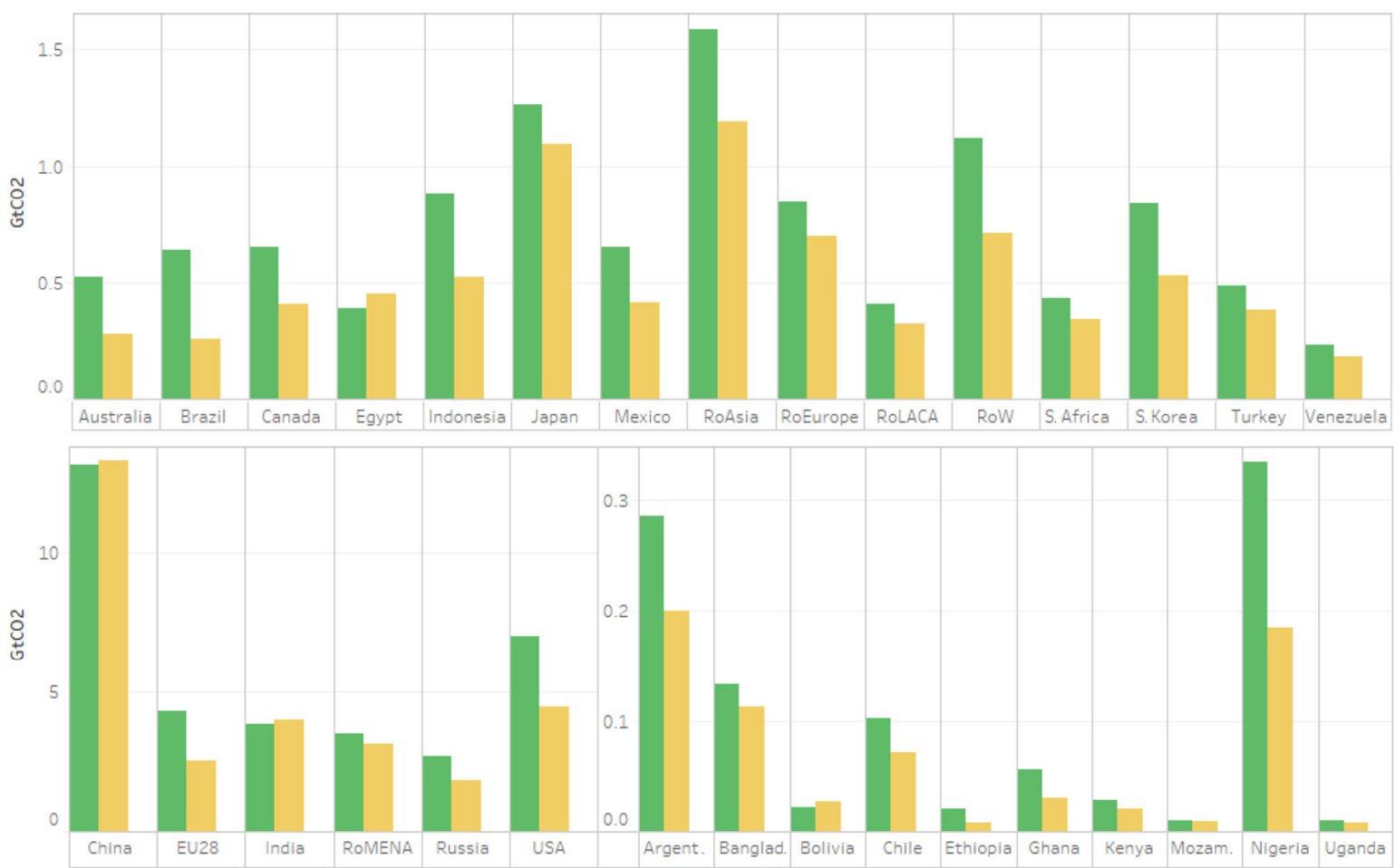

Fig. 6. Stringency of mitigation policy in 2030, $\mathrm{CO}_{2}$ emissions in MPOLICY scenario with respect to SSP2 baseline scenario.

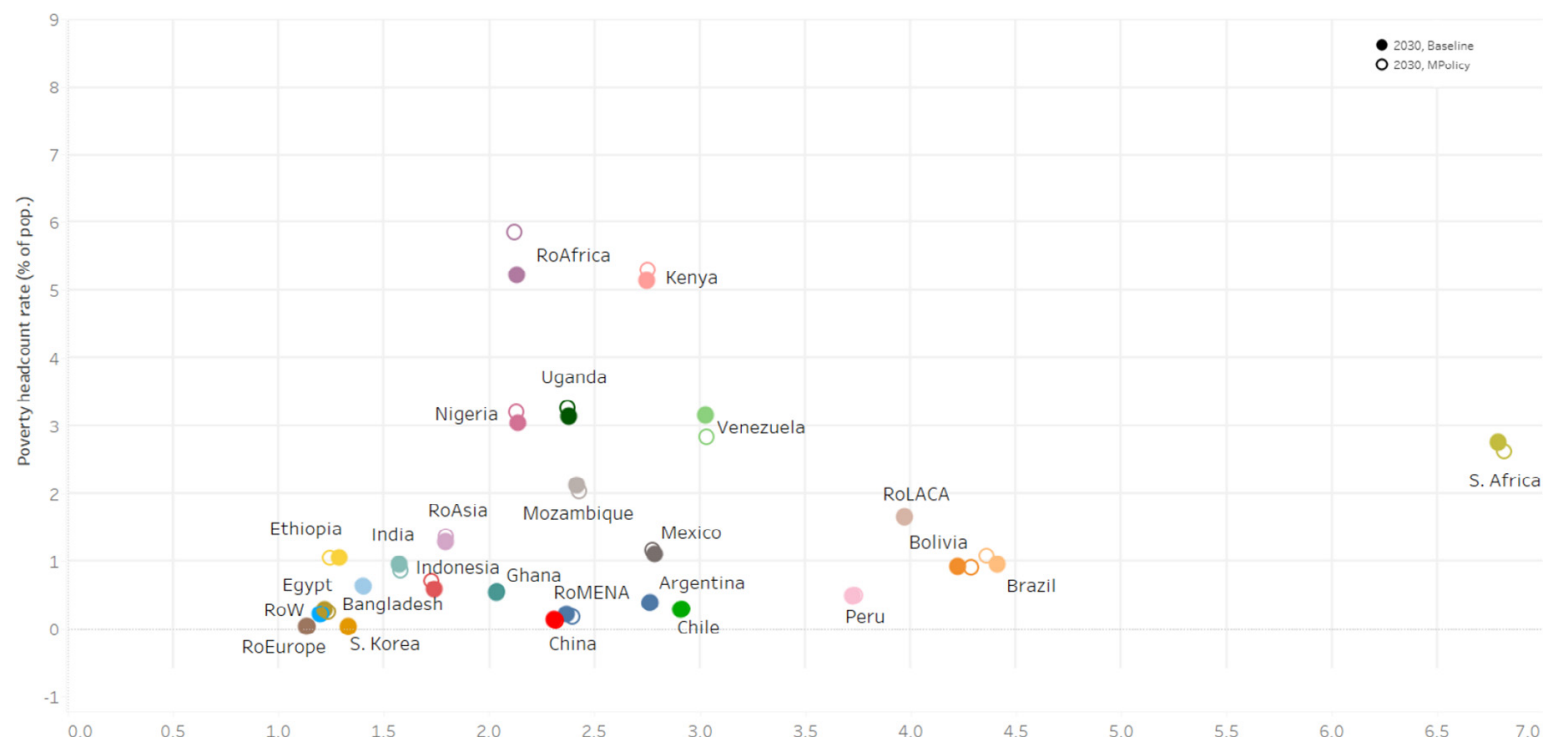

Fig. 7. Palma ratio and poverty prevalence in 2030, MPOLICY and SSP2 baseline scenario.

progressively. The major contributors to this fund are the EU28, providing $41 \%$ of the total amount, and the United States, with $28 \%$.

In the MPOLICY + GCF scenario, the developing countries receive the funds and use them to subsidise clean electricity and R\&D sectors. This recycling scheme determines a small drop of inequality ( $0.1 \%$ globally) by 2030 compared to the MPOLICY scenario. The results are quite heterogeneous at the country level (Fig. 9) and appear unrelated to the share of funds received, but rather to the magnitude of the funds with respect to the country's economy. Ethiopia, which obtains only $2.3 \%$ of the GCF's funds (corresponding to 1.3\% of its GDP in 2030), experiences the highest inequality reduction (5.3\% with respect to the 2030 MPOLICY scenario), which follows a $37.9 \%$ increase of VA share generated in the industrial sector that more than compensate the small contraction in agricultural VA share. In Bolivia, the small fraction of international money that flows into the country (i.e. $0.3 \%$ of its GDP) determines a $0.4 \%$ reduction in inequality, due to the rise in the production of Clean Electricity and R\&D sectors. In Mozambique and India, the Palma ratio shows the highest upsurge, increasing respectively by 0.3 and $0.2 \%$ compared to the MPOLICY scenario. The similarities in the policy effects occur despite disparities in the magnitude of funds flowing into the two countries, respectively $0.6 \%$ and $27 \%$ of the total amount (equal to $0.7 \%$ and $0.3 \%$ of their GDP in 2030), as different mechanisms determine this 


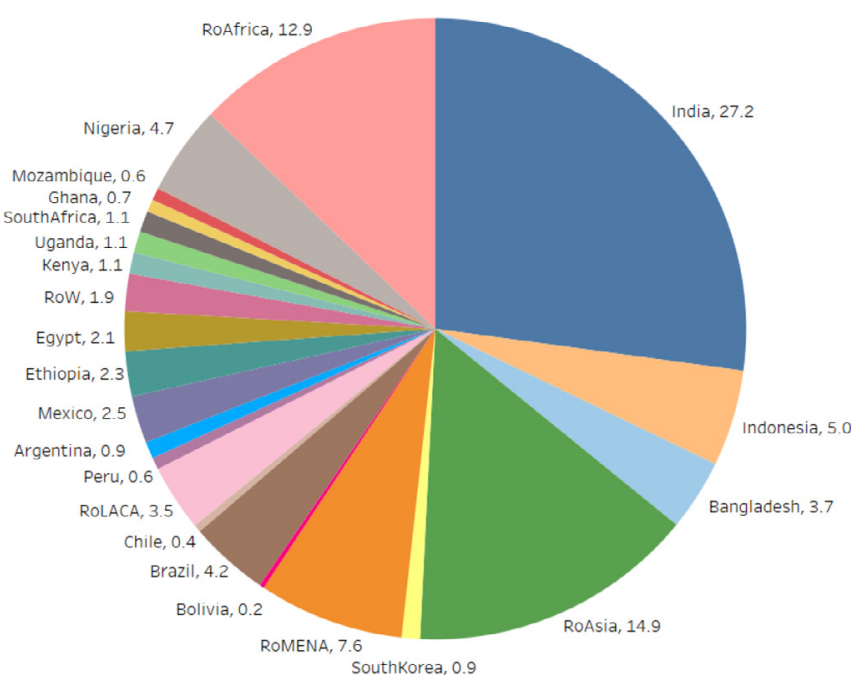

Fig. 8. Developing fund recipients.

outcome: GCF funds boost production in heavy industry sector (expansion of renewables fully offsets the contraction in energy intensive sectors), but determine a negative and equivalent impact on agriculture because of resources flowing into subsidized sectors. In addition, also public expenditure moves towards clean energy and R\&D.

The MPOLICY + GCF scenario has an impact on poverty prevalence, altering both the inequality measure and the average per capita income (Fig. 10). By 2030, poverty worldwide slightly decreases ( -197 thousand poor people) compared to the MPOLICY scenario, with highly heterogeneous outcomes across regions.

The main driver of this impact is the change in per capita GDP that the policy determines. Countries receiving the highest shares from the GCF experience a GDP increase compared to the MPOLICY scenario, which, joined to irrelevant changes in inequality, reduces poverty prevalence in Indonesia $(-0.9 \%)$, RoAfrica $(-0.6 \%)$, RoAsia $(-0.5 \%)$, Brazil $(-0.2 \%)$ and India $(-0.1 \%)$.
Conversely, in Bangladesh, Ethiopia, Uganda and Ghana the influx of international funds causes a rise in poverty compared to the MPOLICY scenario (respectively by $2.4,2.3,1.2$ and $1.2 \%$ ). Behind this result is a regressive effect of subsidies on the GDP passing through the trade balance. The support to Clean Electricity and R\&D determines a flow of labour and capital towards these sectors that is detrimental to other production sectors (in particular light industry), which see a reduction in output. This also determines a contraction in exports not compensated by a rise in the exportation of Clean Electricity and $R \& D$, whose traded production is limited.

Mozambique and Egypt show an interesting pattern: in spite of a limited influx from the GCF $(0.6 \%$ and $2.1 \%$ of the fund), they experience a further substantial drop in poverty prevalence compared to the MPOLICY scenario, namely $-4 \%$ and $-1.5 \%$. For both countries, the rise in per capita income largely compensates respectively a small and null increase in inequality. The subsidy, especially to Clean Electricity, has a progressive impact on these two economies, stimulating industrial production, which is the leading export sector and, therefore, determining an improvement in the trade balance.

Despite the moderate decrease worldwide of poverty prevalence linked to the introduction of the GCF scheme compared to MPOLICY alone, its magnitude remains above the baseline level in 2030 (about 3.2 million people more than in the baseline scenario).

\section{Discussion}

Our results show that the implementation of the emissions reduction objectives stated in the NDCs implies some trade-offs with poverty reduction efforts. Although the overall impact is rather limited, the economic loss imposed by the mitigation policies is the main channel through which countries proposing a relatively more ambitious target are penalized more than others.

Even though not fully comparable at the geographical scale, our results are consistent with other recent estimates that assess the cost of mitigation action under the Paris Agreement by using

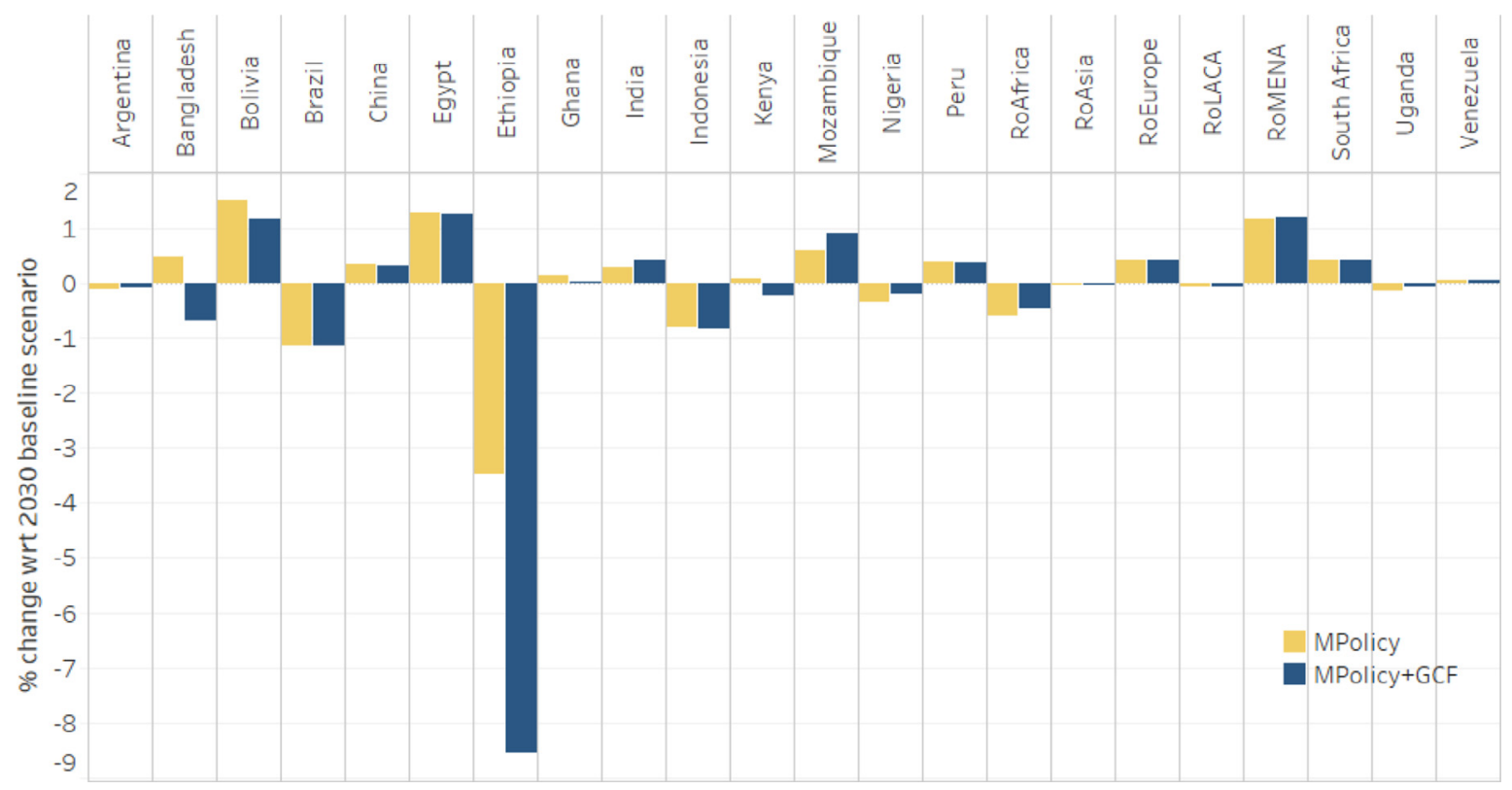

Fig. 9. Palma ratio in MPOLICY and MPOLICY + GCF scenarios, \%change w.r.t 2030 SSP2 baseline scenario. 


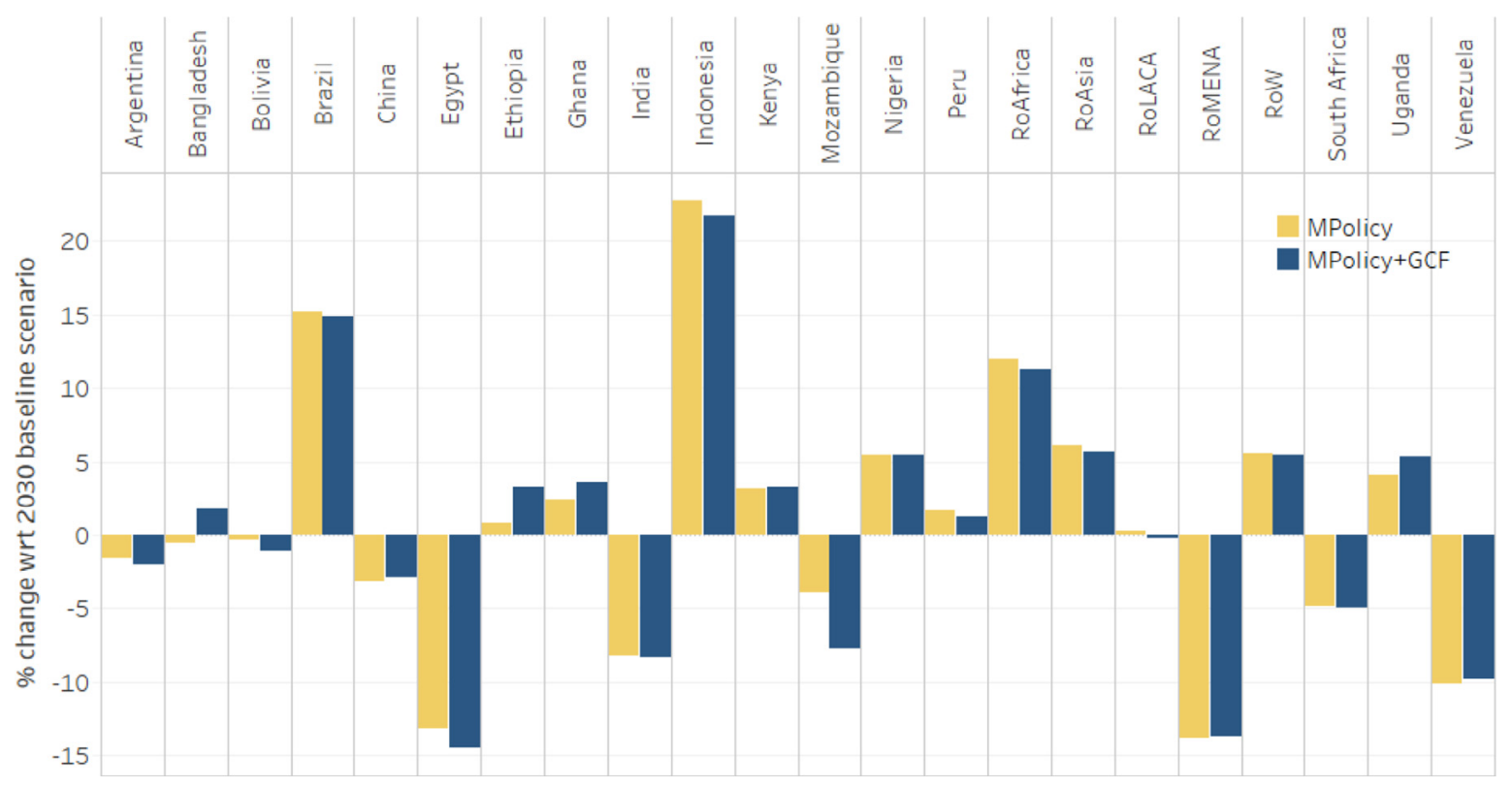

Fig. 10. Poverty headcount rate in MPOLICY and MPOLICY + GCF scenarios, \%change wrt 2030 SSP2 baseline scenario.

similar scenario assumptions (see Aldy et al., 2016). However, some caveats must be noted.

In the case of Indonesia and Brazil, which show the highest GDP losses, we need to acknowledge that our model does not fully capture the economic potential of these countries in terms of emission reduction from the forestry sector. Although both their mitigation objectives are economy-wide, reforestation and reduced deforestation are certainly an economically viable mitigation opportunity for these countries (Smith et al., 2014). According to Gurgel and Paltsev (2017), modelling also the non-GHG targets Brazil has pledged to undertake (on land use, energy efficiency and renewables), country's GDP in 2030 is projected to be $0.7 \%$ lower than the BAU. On the other hand, it should be recognized that the high uncertainty in estimating this kind of policies, and especially measuring land use changes, remains an issue.

Similarly, China's action, as stated in both the NDC and the subsequent 13th Five Year Plan (2016-2020), is broader than the quantitative carbon intensity target used for our analysis. In particular, the planned increase in the non-fossil fuel share and the recently-imposed limit on coal consumption, if maintained up to 2030, might lead to steeper emission reductions (and potentially higher costs) than those projected in our mitigation scenario. These issues, along with the importance of the actual policy design and implementation, relate to the broader discussion on how the heterogeneous and multidimensional nature of the emission reduction policies included in the new climate architecture should be assessed (Aldy et al., 2018).

In addition, in our analysis mitigation actions are achieved unilaterally by each country (excluding the EU-28 members). The literature usually agrees on the fact that the costs of climate action are lower if cooperative mechanisms are implemented (Clarke et al., 2009). However, despite the fact that the Paris Agreement explicitly opens up to the possibility for countries to use "Internationally Transferred Mitigation Outcomes" (ITMOs), at the moment there are not enough elements to figure out how such a mechanism will be designed.

Another important consideration is that our results stem from a socio-economic scenario characterised by sustained growth rates, but they present some similarities with the optimistic trajectory described in Ravallion (2013). It is worth noticing that alternative scenarios considering lower GDP growth or higher population growth could determine a slower reduction of poverty prevalence in the baseline scenario. However, the comparative outcome of the mitigation policy with respect to the baseline scenario in terms of poverty and inequality should not be altered by a lower GDP growth (or carbon intensity). A sensitivity analysis on scenario assumptions could be an interesting topic for future research.

Moreover, the results presented in the above sections consider only possible abatement cost for the society without accounting for potential co-benefits or future avoided damages (and costs) induced by emission reduction action. Mitigation policies are indeed proven to positively affect the living conditions of the poor by reducing local air pollution, whose benefits in terms of increased human health and reduced mortality are estimated to exceed marginal abatement costs especially in developing countries (West et al., 2013; Xie et al., 2018). In addition, recent literature shows that long-term climate change impacts will have strong distributional and poverty implications (Dennig, Budolfson, Fleurbaey, Siebert, \& Socolow, 2015). Not accounting for all these elements therefore may imply an overestimation of emission abatement costs.

Finally, our results represent a worst-case scenario in terms of mitigation policy cost and implications on selected SDG indicators because we use a recycling scheme not directly stimulating investments but distributing revenues to households or, in the case of the climate fund transfers, subsidizing specific sectors.

This notwithstanding, this is to our knowledge the first assessment of the impact of Paris Agreement on poverty and inequality at global scale. From a methodological point of view, acknowledging all the caveats that apply to the proposed approach, our study shows that linking empirical social SDG indicators to a CGE model, allows the estimation of future trends of the "Poverty headcount ratio" and the "Palma ratio" indicators under different scenarios and policy interventions for a broad number of countries.

\section{Conclusions}

The output of our analysis makes an important contribution to the literature on the linkages between climate change policy and sustainable development, and makes it possible to formulate pol- 
icy recommendations that inform the ongoing debate on the implementation of the Paris Agreement and the Green Climate Fund.

In particular, if we consider the full implementation of the emission reduction contributions stated in the NDCs, the Paris Agreement is projected to slow down poverty reduction compared to the reference scenario. Despite the heterogeneity of results, the effect is stronger for countries that proposed a relatively more stringent mitigation component in their NDC, whereas countries with a loose mitigation target are likely to experience lower policy costs and a consequent competitive advantage. However, the aggregate effect of current NDCs on poverty headcounts is not so broad, accounting for an increase of $4.2 \%$ globally in 2030 compared to the baseline scenario. The effect on countries' inequality is even more limited. In many cases, the small equity-driven, pro-poor effect induced by a stringent mitigation objective is cancelled out by the cost of the policy that lead to an overall rise in poverty prevalence in 2030 compared to the reference scenario. Ethiopia represents an exception. The great expansion of clean electricity sector is able to foster industrial development. Interestingly, the decrease in inequality in this case is close to offset the losses the African country experiences because of the implementation of a stringent mitigation objective.

By introducing the possibility of distributing a portion of carbon revenues through a climate fund to support developing countries we can infer some implications for both the donor and the recipient countries. Specifically, by assuming an equal share of proceeds from the ETS or carbon tax among developed countries, the maximum amount of revenues they are required to donate to reach the pledged funds is $7 \%$ in 2020 , after which the burden starts to decrease. In most developing countries that receive international financial support in the form of sector-specific subsidies, it accelerates poverty reduction efforts compared to the mitigation scenario with internal recycling of revenues. In big recipient countries, the funds lead to a GDP increase and a consequent reduction in poverty prevalence. However, some of the least developed countries show a regressive effect of subsidies to Clean Electricity and R\&D, which, by attracting resources, are detrimental to other production sectors, which in turn experience a reduction of output and a contraction of exports. Mozambique and Egypt show opposite results as the limited amount of funds manages to decrease poverty prevalence, especially due to the subsidy to Clean Electricity, which stimulates one of the leading export sectors, i.e. heavy industry, and, therefore, determines an improvement in the trade balance. Worldwide, in the scenario including climate fund transfers, poverty slightly decreases even though the magnitude does not manage to offset the increase experienced in the mitigation policy scenario with internal recycling of revenue.

Overall, we observe that the relative magnitude of funds flowing into beneficiary countries is a crucial factor in making the international climate flows a pro-poor instrument, as it is more likely to observe a reduction in poverty in countries that receive a higher amount of funds proportional to the size of their economy. Therefore, the amount of funds provided and the allocation scheme matter for determining the final outcome on poverty prevalence.

However, it is worth emphasizing that climate finance's major purpose is to spread good practices and technologies for mitigation and adaptation, and it should therefore be considered as additional to traditional funds for tackling other sustainable development targets. Nevertheless, our findings would suggest the need to prioritize policies that jointly address climate change mitigation and socio-economic development. The results presented here make therefore a strong case for the reinforcement of those mechanisms that within the UNFCCC aim at contributing to GHG emission mitigation while supporting sustainable development.
Crucially, it should be recalled that these results must be judged with caution: although it is reasonable to think that climate policy per se and its cost will imply a slight increase in poverty prevalence, if we also take into account the co-benefits of mitigation action and the avoided climate-induced damages, in the longterm we very likely will find a reversal of the results in favour of a poverty reduction in both mitigation scenarios.

\section{Acknowledgments}

The authors are grateful to Enrica De Cian, Johannes Emmerling, Henry Lee, Ramiro Parrado and Francesco Vona for feedback on an earlier draft of this article as well as to three anonymous referees for their valuable comments. This work was supported by the People Programme (Marie Curie Actions) of the European Union's Seventh Framework Programme FP7/2007-2013/ under REA grant agreement number 609642.

\section{Declaration of Competing Interest}

None.

\section{Appendix A. Supplementary data}

Supplementary data to this article can be found online at https://doi.org/10.1016/j.worlddev.2019.05.015.

\section{References}

Aldy, J., Pizer, W., Tavoni, M., Aleluia Reis, L., Akimoto, K., Blanford, G., ... Sano, F. (2016). Economic tools to promote transparency and comparability in the Paris agreement. Nature Climate Change, 6(11), 1000-1004. https://doi.org/10.1038/ nclimate3106.

Aldy, J., Pizer, W., Akimoto, K., Aleluia Reis, L., Carraro, C., \& Tavoni, M. (2018). Learning from Nationally Determined Contributions. CMCC Research Papers, Issue RP0286.

Alvaredo, F., \& Gasparini, L. (2015). Recent trends in inequality and poverty in developing countries. In A. B. Atkinson \& F. Bourguignon (Eds.), Handbook of Income Distribution. Elsevier B.V..

Atkinson, T. (1970). On the measurement of inequality. Journal of Economic Theory, 2, 244-263.

Barbier, E. B. (2014). Climate change mitigation policies and poverty. WIREs Climate Change, 5, 483-491. https://doi.org/10.1002/wcc.281.

Beg, N., Morlot, J. C., Davidson, O., Afrane-Okesse, Y., Tyani, L., Denton, F., ... Rahman, A. A. (2002). Linkages between climate change and sustainable development. Climate Policy, 2, 129-144. https://doi.org/10.3763/cpol.2002.0216.

Boccanfuso, D., Decaluwé, B., \& Savard, L. (2003). Poverty, income distribution and CGE modeling: Does the functional form of distribution matter?, Centre interuniversitaire sur le risque, les politiques économiques et l'emploi Cahier de recherche/Working Paper 03-32

Bohringer, C., \& Löschel, A. (2006). Computable general equilibrium models for sustainability impact assessment: Status quo and prospects. Ecological Economics, 60(1), 49-64.

Bourguignon, F., \& Morrisson, C. (1998). Inequality and development: The role of dualism. Journal of Development Economics, 57, 233-257.

Bourguignon, F., Ferreira, F., \& Lustig, N. (2005). The microeconomics of income distribution dynamics in East Asia and Latin America. Washington, DC: World Bank Report.

Büchs, M., Bardsley, N., \& Duwe, S. (2011). Who bears the brunt? Distributional effects of climate change mitigation policies. Critical Social Policy, 31(2), 285-307. https://doi.org/10.1177/0261018310396036.

Bussolo, M., \& Lay, J. (2003). Globalisation and poverty changes in Colombia, OECD working paper No. 226.

Callan, T., Lyons, S., Scott, S., Tol, R. S. J., \& Verde, S. (2009). The distributional implications of a carbon tax in Ireland. Energy Policy, 37(2), 407-412.

Clarke, L., Edmonds, J., Krey, V., Richels, R., Rose, S., \& Tavoni, M. (2009). International climate policy architectures: Overview of the EMF 22 international scenarios. Energy Economics, 31(Suppl. 2), S64-S81.

Cobham, A., Schlogl, L., \& Sumner, A. (2016). Inequality and the tails: The palma proposition and ratio. Global Policy, 7(1).

Dennig, F., Budolfson, M. B., Fleurbaey, M., Siebert, A., \& Socolow, R. H. (2015). Inequality, climate impacts on the future poor, and carbon prices. PNAS, 112 (52), 15827-15832.

Eboli, F., Parrado, R., \& Roson, R. (2010). Climate change feedback on economic growth: Explorations with a dynamic general equilibrium model. Environment and Development Economics, 15(5), 515-533. 
Ferreira, F. H. G., Leite, P. G., \& Ravallion, M. (2010). Poverty reduction without economic growth?: Explaining Brazil's poverty dynamics, 1985-2004. Journal of Development Economics, 93(1), 20-36.

Ferreira, F. H. G., \& Ravallion, M. (2009). Poverty and inequality: The global context. In W. Salverda, B. Nolan, \& T. Smeeding (Eds.), The Oxford handbook of economic inequality (pp. 2009). Oxford: Oxford University Press.

GCF - Green Climate Fund (2014). Decisions of the board - Sixth meeting of the board 19-21 February 2014, GCF/B.06/18, 17 April 2014, agenda item 11 (pag. 4) Accessed March 10, 2017 https://www.greenclimate.fund/documents/20182/ 24940/GCF_B.06_18_-_Decisions_of_the_Board_-_Sixth_Meeting_of_the_ Board_19-21_February_2014.pdf/0ba2bfb2-9cbe-41e1-83a6-c5d5662fb463.

Goulder, L. H. (2013). Climate change policy's interactions with the tax system. Energy Economics, 40(Suppl. 1), S3-S11.

Grottera, C., Pereira, A. O. J., \& La Rovere, E. L. (2017). Impacts of carbon pricing on income inequality in Brazil. Journal Climate and Development, 9(1).

Gurgel, A. C., \& Paltsev, S. (2017). The Impacts of the Brazilian NDC and their contribution to the Paris Agreement on Climate Change. GTAP 2017 conference paper, presented at the 20th annual conference on global economic analysis.

Heltberg, R. (2002). The poverty elasticity of growth, WIDER Discussion Papers. World Institute for Development Economics (UNU-WIDER). Working paper No. 2002 21.

Hertel, T., Verma, M., Ivanic, M., \& Rios, A. (2011). GTAP-POV: A framework for assessing the national poverty impacts of global economic and environmental policies. GTAP technical paper No. 31 .

Hilderink, H., Lucas, P., \& Kok, M. (2009). Beyond 2015: Long-term development and the Millennium Development Goals. Netherlands Environmental Assessment Agency (PBL).

Hussein, Z., Hertel, T., \& Golub, A. (2013). Climate change mitigation policies and global poverty. Environmental Research Letters. https://doi.org/10.1088/17489326/8/3/035009.

Iyer, G., Calvin, K., Clarke, L., Edmonds, J., Hultman, N., Hartin, C., ... Pizer, W. (2018). Implications of sustainable development considerations for comparability across nationally determined contributions. Nature Climate Change, 8, 124-129. https://doi.org/10.1038/s41558-017-0039-z.

Jakob, M., \& Steckel, J. K. (2014). Climate change mitigation could harm development in poor countries. WIREs Climate Change, 5, 161-168. https://doi. org/10.1002/wcc.260.

Loayza, N. V., \& Raddatz, C. (2010). The composition of growth matters for poverty alleviation. Journal of Development Economics, 93(2010), 137-151.

Lofgren, H., Cicowiez, M., \& Diaz-Bonilla, C. (2013). A computable genera equilibrium model for developing country strategy analysis. In P. Dixon \& D. Jorgenson (Eds.), Handbook of computable general equilibrium modeling. .

van der Mensbrugghe, D. (2015). Shared socio-economic pathways and globa income distribution. Conference paper $18^{\text {th }}$ annual conference on global economic analysis.

Montalvo, J. G., \& Ravallion, M. (2010). The pattern of growth and poverty reduction in China. Journal of Comparative Economics, 38, 2-16.

Narayanan, G., Aguiar, B. A., \& McDougall, R. (Eds.). (2012). Global trade, assistance, and production: The GTAP 8 data base. Center for Global Trade Analysis, Purdue University.

Olsen, K. H. (2007). The clean development mechanism's contribution to sustainable development: A review of the literature. Climatic Change, 84(1), 59-73.

Olsson, L., Opondo, M., Tschakert, P., Agrawal, A., Eriksen, S. H., Ma, S., ... Zakieldeen, S. A. (2014). Livelihoods and poverty. In C. B. Field, V. R. Barros, D. J. Dokken, K. J. Mach, M. D. Mastrandrea, T. E. Bilir, M. Chatterjee, K. L. Ebi, Y. O. Estrada, R. C. Genova, B. Girma, E. S. Kissel, A. N. Levy, S. MacCracken, P. R. Mastrandrea, \& L. L. White (Eds.), Climate change 2014: Impacts, adaptation, and vulnerability. Part A: Global and sectoral aspects. Contribution of working group II to the fifth assessment report of the intergovernmental panel on climate change (pp. 793-832). Cambridge, United Kingdom and New York, NY, USA: Cambridge University Press.

O’Neill, B. C., Kriegler, E., Ebi, K. L., Kemp-Benedict, E., Riahi, K., Rothman, D. S., .. Solecki, W. (2017). The roads ahead: narratives for shared socioeconomic pathways describing world futures in the 21st century. Global Environ Change, 42, 169-180. https://doi.org/10.1016/j.gloenvcha.2015.01.004.
Rao, S., Klimont, Z., Leitao, J., Riahi, K., van Dingenen, R., Aleluia, Reis L., ... Fujimori, S. (2016). A multi-model assessment of the co-benefits of climate mitigation for global air quality. Environmental Research Letters, 11(12).

Ravallion, M. (1997). Can high-inequality developing countries escape absolute poverty?". Economics Letters, 56, 51-57.

Ravallion, M. (2001). Growth, inequality and poverty: Looking beyond averages. World Development, 29(11), 1803-1815.

Ravallion, M. (2003). Inequality convergence. Economics Letters, 80, 351-356.

Ravallion, M. (2013). How long will it take to lift one billion people out of poverty? World Bank Research Observer, 28(2), 139-158.

Ravallion, M. (2014). Income inequality in the developing world. Science, 344(6186), $851-855$.

Ravallion, M., \& Chen, S. (1997). What can new survey data tell us about recent changes in distribution and poverty? The World Bank Economic Review, 11, 357-382.

Smith, P., Bustamante, M., Ahammad, H., Clark, H., Dong, H., Elsiddig, E. A., .. Tubiello, F. (2014). Agriculture, forestry and other land use (AFOLU). In O. Edenhofer, R. Pichs-Madruga, Y. Sokona, E. Farahani, S. Kadner, K. Seyboth, A. Adler, I. Baum, S. Brunner, P. Eickemeier, B. Kriemann, J. Savolainen, S. Schlömer, C. von Stechow, T. Zwickel, \& J. C. Minx (Eds.), Climate Change 2014: Mitigation of climate change. contribution of working group III to the fifth assessment report of the intergovernmental panel on climate change. Cambridge, United Kingdom and New York, NY, USA: Cambridge University Press.

von Stechow, C., McCollum, D., Riahi, K., Minx, J. C., Kriegler, E., van Vuuren, D. P., ... Edenhofer, O. (2015). Integrating global climate change mitigation goals with other sustainability objectives: a synthesis. Annual Review of Environment and Resources, 40, 363-394. https://doi.org/10.1146/annurev-environ-021113095626.

von Stechow, C., Minx, J. C., Riahi, K., Jewell, J., McCollum, D. L., Callaghan, M. W., ... Baiocchi, G. (2016). $2{ }^{\circ} \mathrm{C}$ and SDGs: united they stand, divided they fall? Environmental Research Letters, 11. https://doi.org/10.1088/1748-9326/11/3/ 034022034022.

Steckel, J. C., Brecha, R. J., Jakob, M., Strefler, J., \& Luderer, G. (2013). Development without energy? Assessing future scenarios of energy consumption in developing countries. Ecological Economics, 90, 53-67. https://doi.org/10.1016/ j.ecolecon.2013.02.006.

Swart, R., Robinson, J., \& Cohen, S. (2003). Climate change and sustainable development: Expanding the options. Climate Policy, 3, S19-S40. https://doi. org/10.1016/j.clipol.2003.10.010.

Treisman, D. (2007). What Have We Learned About the Causes of Corruption From Ten Years of Cross-National Empirical Research? Annual Review of Political Science, $10, \quad 211-244 . \quad$ https://doi.org/10.1146/annurev. polisci.10.081205.095418.

United Nations (2015). Resolution adopted by the General Assembly on 25 September 2015. A/RES/70/1 http://www.un.org/ga/search/view_doc.asp?symbol=A/RES/ $70 / 1$ \& Lang $=$ E.

United Nations (2017). Report of the inter-agency and expert group on sustainable development goal indicators E/CN.3/2017/2. Economic and Social Council http:// unstats.un.org/unsd/statcom/48th-session/documents/2017-2-SDG-IAEG-EE. pdf.

UNFCCC (2015). Adoption of the Paris Agreement. Paris: UNFCCC Conference of the Parties. Twenty-first session Paris, 30 Nov. to 11 Dec. 2015.

UNU-WIDER (2017). World income inequality database (WIID3.4). United Nations University World Institute for Development Economics Research.

West, J. J., Smith, S. J., Silva, R. A., Naik, V., Zhang, Y., Adelman, Z., ... Lamarque, J.-F. (2013). Co-benefits of mitigating global greenhouse gas emissions for future air quality and human health. Nature Climate Change, 3, 885. https://doi.org/ $10.1038 /$ nclimate2009.

World Bank (2018). World development indicators, 1960-2014 Available at: http://data.worldbank.org/data-catalog/world-development-indicators.

WRI (2016). CAIT data explorer Available at:. Washington, DC: World Resources Institute http://cait.wri.org/

Xie, Y., Dai, H., Xu, X., Fujimori, S., Hasegawa, T., Yi, K., ... Kurata, G. (2018). Cobenefits of climate mitigation on air quality and human health in Asian countries. Environment International, 119, 309-318. https://doi.org/10.1016/j. envint.2018.07.008. 